OPEN ACCESS

Edited by:

Luciana Venturini Rossoni, University of São Paulo, Brazil

Reviewed by: Jamaira A. Victorio,

Campinas State University, Brazil Maria Andreia Delbin,

Campinas State University, Brazil

${ }^{*}$ Correspondence: Daniella Bonaventura danibona@icb.ufmg.br; danibona@gmail.com

Specialty section: This article was submitted to

Vascular Physiology,

a section of the journal

Frontiers in Physiology

Received: 11 November 2020 Accepted: 22 December 2020

Published: 15 January 2021

Citation

Reis Costa DEF, Silveira ALM,

Campos GP, Nóbrega NRC Araújo NF, Borges LF, Capettini LSA,

Ferreira AVM and Bonaventura $D$ (2021) High-Carbohydrate Diet Enhanced the Anticontractile Effect of Perivascular Adipose Tissue Through Activation

of Renin-Angiotensin System.

Front. Physiol. 11:628101. doi: 10.3389/fphys.2020.628101

\section{High-Carbohydrate Diet Enhanced the Anticontractile Effect of Perivascular Adipose Tissue Through Activation of Renin-Angiotensin System}

\author{
Daniela Esteves Ferreira dos Reis Costa', Ana Letícia Malheiros Silveira², \\ Gianne Paul Campos ${ }^{1}$, Natália Ribeiro Cabacinha Nóbrega ${ }^{1}$, Natália Ferreira de Araújo', \\ Luciano de Figueiredo Borges ${ }^{3}$, Luciano dos Santos Aggum Capettini', \\ Adaliene Versiani Matos Ferreira ${ }^{2,4}$ and Daniella Bonaventura ${ }^{1 *}$
}

${ }^{1}$ Department of Pharmacology, Biological Sciences Institute, Federal University of Minas Gerais, Belo Horizonte, Brazil, ${ }^{2}$ Department of Biochemistry and Immunology, Biological Sciences Institute, Federal University of Minas Gerais, Belo Horizonte, Brazil, ${ }^{3}$ Department of Biological Sciences, Morphophysiology \& Pathology Sector, Federal University of São Paulo, São Paulo, Brazil, ${ }^{4}$ Department of Nutrition, Nursing School, Federal University of Minas Gerais, Belo Horizonte, Brazil

The perivascular adipose tissue (PVAT) is an active endocrine organ responsible for release several substances that influence on vascular tone. Increasing evidence suggest that hyperactivation of the local renin-angiotensin system (RAS) in the PVAT plays a pivotal role in the pathogenesis of cardiometabolic diseases. However, the local RAS contribution to the PVAT control of vascular tone during obesity is still not clear. Since the consumption of a high-carbohydrate diet ( $\mathrm{HC}$ diet) contributes to obesity inducing a rapid and sustained increase in adiposity, so that the functional activity of PVAT could be modulated, we aimed to evaluate the effect of $\mathrm{HC}$ diet on the PVAT control of vascular tone and verify the involvement of RAS in this effect. For that, male Balb/c mice were fed standard or $\mathrm{HC}$ diet for 4 weeks. Vascular reactivity, histology, fluorescence, and immunofluorescence analysis were performed in intact thoracic aorta in the presence or absence of PVAT. The results showed that HC diet caused an increase in visceral adiposity and also in the PVAT area. Phenylephrine-induced vasoconstriction was significantly reduced in the $\mathrm{HC}$ group only in the presence of PVAT. The anticontractile effect of PVAT induced by HC diet was lost when aortic rings were previously incubated with angiotensin-converting enzyme inhibitor, Mas, and $\mathrm{AT}_{2}$ receptors antagonists, PI3K, nNOS, and iNOS inhibitors, hydrogen peroxide $\left(\mathrm{H}_{2} \mathrm{O}_{2}\right)$ decomposing enzyme or non-selective potassium channels blocker. Immunofluorescence assays showed that both Mas and $\mathrm{AT}_{2}$ receptors as well as nNOS and iNOS isoforms were markedly expressed in the PVAT of the HC group. Furthermore, the PVAT from HC group also exhibited higher nitric oxide (NO) and hydrogen peroxide bioavailability. Taken together, these findings suggest that the anticontractile effect of PVAT induced by HC diet involves the signaling cascade triggered by the renin-angiotensin system through the activation 
of Mas and $\mathrm{AT}_{2}$ receptors, PI3K, nNOS, and iNOS, leading to increased production of nitric oxide and hydrogen peroxide, and subsequently opening of potassium channels. The contribution of PVAT during HC diet-induced obesity could be a compensatory adaptive characteristic in order to preserve the vascular function.

Keywords: PVAT, obesity, high-carbohydrate diet, renin-angiotensin system, nitric oxide, hydrogen peroxide

\section{INTRODUCTION}

According to the World Health Organization (WHO), obesity is defined as abnormal or excessive fat accumulation in adipose tissue, which is not only a large storage for lipids but also a dynamic endocrine organ that secretes several bioactive substances (World Health Organization [WHO], 2016). The worldwide prevalence of obesity nearly tripled between 1975 and 2016 in which more than 1.9 billion adults were overweight and of those over 650 million adults were obese (World Health Organization [WHO], 2016). As the population is becoming increasingly overweight and obese, the typical Western diet that contains large amounts of lipids and refined carbohydrates has been of greater concern.

Different dietary approaches in animal models have been shown to be crucial to elucidate the mechanistic effects of specific diets in the development of obesity. The detrimental effect of high-fat diets is already well documented in previous studies demonstrating that the long-term administration of $40-60 \%$ fat diets promotes metabolic changes, increased adiposity, and plasma levels of proinflammatory cytokines (Flanagan et al., 2008; Gregersen et al., 2012). Similarly, the consumption of high-refined carbohydrate diets (HC diet) also induces metabolic disorders (Ferreira et al., 2011; Oliveira et al., 2013), but it is taken into less consideration. The HC diet showed induce a rapid and sustained increase in adiposity, glucose intolerance, low insulin sensitivity, and atherogenic dyslipidemia, contributing to the development of obesity and related diseases (Porto et al., 2011; Oliveira et al., 2013).

Obesity is commonly related to a wide spectrum of cardiovascular diseases (Poirier et al., 2006; Koliaki et al., 2018). Although visceral adipose tissue is usually associated with a higher risk of cardiovascular diseases, there is a potential interest to study the role of fat accumulation around blood vessels in the pathogenesis of vascular dysfunction. The perivascular adipose tissue (PVAT) surrounds the adventitious layer of blood vessels in several vascular beds. It not only acts as a structural support and protection for most blood vessels, but it also secretes a variety of bioactive molecules that influence on vascular tone

Abbreviations: ACh, acetylcholine; Ang II, angiotensin II; Ang 1-7, angiotensin 17; $\mathrm{AT}_{2}$, angiotensin II receptor type II; $\mathrm{CaCl}_{2}$, calcium chloride; Emax, maximum effect; eNOS, endothelial nitric oxide synthase; HC diet, high-carbohydrate diet; $\mathrm{H}_{2} \mathrm{O}_{2}$, hydrogen peroxide; iNOS, inducible nitric oxide synthase; $\mathrm{KCl}$, potassium chloride; $\mathrm{KH}_{2} \mathrm{PO}_{4}$, monopotassium phosphate; Mas, angiotensin 1-7 receptor; $\mathrm{MgSO}_{4}$, magnesium sulphate; $\mathrm{NaCl}$, sodium chloride; $\mathrm{NaHCO}_{3}$, sodium bicarbonate; $\mathrm{nNOS}$, neuronal nitric oxide synthase; $\mathrm{NO}$, nitric oxide; $\mathrm{pD}_{2}$, potency; PE, phenylephrine; PI3K, phosphatidylinositol 3-kinase; PVAT, perivascular adipose tissue; RAS, renin-angiotensin system; TEA, tetraethylammonium. and on susceptibility to the pathogenesis of cardiovascular diseases related to obesity (Gao, 2007; Szasz et al., 2013; Majesky, 2015).

Due to its high plasticity through changes in adipocyte morphology or balance of vasoactive factors secreted, the PVAT is able to adapt to different physiological and pathological conditions (Galvez-Prieto et al., 2012; Van de Voorde et al., 2014). Under physiological conditions, the PVAT usually induces an anticontractile effect secreting predominantly vasodilator substances such as adiponectin (Fesus et al., 2007), leptin (Dashwood et al., 2011), angiotensin 1-7 (Lee et al., 2009), hydrogen peroxide $\left(\mathrm{H}_{2} \mathrm{O}_{2}\right)$ (Gao et al., 2007), and nitric oxide (NO) (Malinowski et al., 2008). However, under pathological conditions, the PVAT can exhibit a vasoconstrictor profile secreting mainly angiotensin II (Galvez-Prieto et al., 2008) and superoxide anions (Ketonen et al., 2010). This plasticity of the PVAT is important for the maintenance of vascular homeostasis as it may influence on progression or regression of vascular diseases (Britton and Fox, 2011; Brown et al., 2014).

The mechanisms that mediate the role of PVAT on the control of vascular tone during obesity are still under study. Increasing evidence suggest that hyperactivation of the local renin-angiotensin system (RAS) in the PVAT plays a pivotal role in the pathogenesis of cardiometabolic diseases (Aghamohammadzadeh et al., 2012), since the essential components of RAS have been shown to be expressed in PVAT, specially $\mathrm{AT}_{1}$ and $\mathrm{AT}_{2}$ receptors (Galvez-Prieto et al., 2008), and also Mas receptors (Nobrega et al., 2019). $\mathrm{AT}_{1}$ receptors are responsible for most biological effects of angiotensin II, which includes vasoconstriction, sodium retention, aldosterone release, cell proliferation, cardiac and vascular hypertrophy, oxidative stress, and inflammation (Faria-Costa et al., 2014), whereas $\mathrm{AT}_{2}$ receptors have opposite effects that counterbalance those mediated by the classical activation of $\mathrm{AT}_{1}$ receptors (Rubio-Ruiz et al., 2014). However, the counter regulatory response to most of the deleterious effects of $\mathrm{AT}_{1}$ receptors is mainly attributed to angiotensin 1-7, which binds to Mas receptors (Bader et al., 2014) and also to $\mathrm{AT}_{2}$ receptors (Castro et al., 2005), promoting several protective effects in the vascular system, including vasodilation (Ren et al., 2002), reduction of oxidative stress (Raffai et al., 2011) and anti-inflammatory effects (Lee et al., 2015), especially in pathological conditions.

Given that the local RAS contribution to the role of PVAT on the vascular tone during obesity needs to be better elucidated, and that the relationship between obesity induced by HC diet and PVAT has not yet been investigated, we aimed to evaluate the effect of HC diet on the PVAT control of vascular tone and verify the involvement of RAS in this effect. 


\section{MATERIALS AND METHODS}

\section{Experimental Animals and Dietary Treatment}

All protocols with animal study were conducted in accordance with the Brazilian Council of Animal Research Guidelines (CONCEA), reviewed and approved by the Ethics Committee on Animal Use of Federal University of Minas Gerais (UFMG) under the protocol number 225/2013. Male Balb/c mice, 8 weeks of age, were obtained from the Center of Bioterism of Biological Sciences Institute of UFMG and kept under controlled conditions of temperature and luminosity (light-dark cycle of $12 \mathrm{~h}$ ), with free access to water and food.

The animals were randomly divided into two groups: control and HC. The control group received a standard diet (Nuvilab CR-1), while the $\mathrm{HC}$ group received a refined carbohydrate enriched diet (HC diet) for 4 weeks. The HC diet was prepared using $45 \%$ (395 g) of the standard diet (powder), added to $45 \%$ (395 g) of condensed milk and 10\% (83.79 g) of refined sugar, mixed until it forms a homogeneous mass to make small pellets. The macronutrient composition of the standard diet $(4.0 \mathrm{kcal} / \mathrm{g})$ was $65.8 \%$ carbohydrate, $3.1 \%$ fat, and $31.1 \%$ protein, obtained from the manufacturer's information, while the macronutrient composition of the $\mathrm{HC}$ diet $(4.4 \mathrm{kcal} / \mathrm{g})$ was $74.2 \%$ carbohydrate, $5.8 \%$ fat, and $20 \%$ protein, obtained from the nutritional analysis carried out by Oliveira et al. (2013).

\section{Assessment of Body Weight, Food Intake, and Adiposity Index}

Animals were weighed once a week and the food intake was measured twice a week. Samples of epididymal, retroperitoneal, and mesenteric adipose tissues were weighed to evaluate the adiposity index, according to the equation below (Oliveira et al., 2013).

$$
\text { Adiposity Index }(\%)=\frac{\sum \text { Adipose Tissues Weight }}{\text { Animal Weight }} \times 100
$$

\section{Vascular Reactivity}

Animals were euthanized by decapitation and the thoracic aorta was carefully isolated and sectioned into two rings with $3 \mathrm{~mm}$ length each. In one of the rings the PVAT was completely removed while the other was kept intact. The aortic rings were placed between two stainless-steel stirrups and connected to an isometric tension transducer (World Precision Instruments, Inc., Sarasota, FL, United States). The vessels were placed in organ chambers containing modified Krebs-Henseleit physiological solution (mmol/L: $\mathrm{NaCl} 135.0 ; \mathrm{KCl} 5.0 ; \mathrm{KH}_{2} \mathrm{PO}_{4}$ 1.17; $\mathrm{CaCl}_{2}$ 2.5; $\mathrm{MgSO}_{4}$ 1.4; $\mathrm{NaHCO}_{3}$ 20.0; glucose 11.0 ) at $37^{\circ} \mathrm{C}$ with a stable $\mathrm{pH} 7.4$ and gassed with carbogenic mixture $(95 \%$ $\mathrm{O}_{2}$ and $5 \% \mathrm{CO}_{2}$ ) (White Martins, Brazil). After $1 \mathrm{~h}$ of stabilization at a basal tension of $4.9 \mathrm{mN}(0.5 \mathrm{~g})$, the vessels were stimulated with potassium chloride $\left(9 \times 10^{-2} \mathrm{~mol} / \mathrm{L}\right)$ in order to determine its viability. Subsequently, the aortas were previously contracted with phenylephrine (EC 50 PE: $10^{-7} \mathrm{~mol} / \mathrm{L}$ ) and the presence of a functional endothelium was verified by the addition of acetylcholine ( $\left.\mathrm{EC}_{50} \mathrm{ACh}: 10^{-6} \mathrm{~mol} / \mathrm{L}\right)$. The endothelial integrity was considered in a minimum of $80 \%$ relaxation for acetylcholine. To assess the effect of $\mathrm{HC}$ diet on endothelium-dependent vasodilation, cumulative concentrationresponse curves for acetylcholine (ACh $\left.10^{-10}-10^{-4} \mathrm{~mol} / \mathrm{L}\right)$ were obtained in aortas previously contracted with phenylephrine $\left(\mathrm{EC}_{50} \mathrm{PE}: 10^{-7} \mathrm{~mol} / \mathrm{L}\right)$ in the presence or absence of PVAT. Acetylcholine-induced vasodilation was expressed in percentage of relaxation. The effect of $\mathrm{HC}$ diet on vascular contractility was assessed in cumulative concentration-response curves for phenylephrine (PE $\left.10^{-10}-10^{-4} \mathrm{~mol} / \mathrm{L}\right)$ obtained in endotheliumintact aortas in the presence or absence of PVAT. Phenylephrineinduced vasoconstriction was expressed in $\mathrm{mN}$.

In order to investigate the mechanisms underlying the effects of HC diet on the PVAT control of vascular tone, cumulative concentration-response curves for phenylephrine (PE $10^{-10}-10^{-4} \mathrm{~mol} / \mathrm{L}$ ) were only performed in the presence of PVAT previously incubated for $30 \mathrm{~min}$ with one of the following drugs: captopril $\left(10^{-5} \mathrm{~mol} / \mathrm{L}\right.$ - angiotensin converting enzyme inhibitor) (Kikta and Fregly, 1982; Su et al., 2008), A779 ( $10^{-6} \mathrm{~mol} / \mathrm{L}$ - selective Mas receptor antagonist) (Peiró et al., 2013), PD123,319 (10 ${ }^{-6} \mathrm{~mol} / \mathrm{L}$ - selective $\mathrm{AT}_{2}$ receptor antagonist) (Su et al., 2008), LY294,002 (10 ${ }^{-6} \mathrm{~mol} / \mathrm{L}-\mathrm{PI} 3 \mathrm{~K}$ inhibitor) (Jimenez et al., 2010), L-NAME $\left(10^{-4} \mathrm{~mol} / \mathrm{L}\right.$ non-selective NOS inhibitor) (Araújo et al., 2012), L-NNA $\left(10^{-6} \mathrm{~mol} / \mathrm{L}\right.$ - selective eNOS inhibitor) (Araújo et al., 2012; Gonzaga et al., 2018; Nobrega et al., 2019), 1,400 W $\left(10^{-5} \mathrm{~mol} / \mathrm{L}\right.$ - selective iNOS inhibitor) (Garvey et al., 1997), 7Ni $\left(10^{-4} \mathrm{~mol} / \mathrm{L}\right.$ - selective nNOS inhibitor) (Babbedge et al., 1993), catalase $(300 \mathrm{U} / \mathrm{mL}$ - catalyzes the decomposition of hydrogen peroxide) (Gonzaga et al., 2018) or tetraethylammonium (TEA, $10^{-3} \mathrm{~mol} / \mathrm{L}$ - non-selective blocker of potassium channels) (Bonaventura et al., 2011). All concentrations of drugs were based on previous studies abovementioned. Agonist potencies and maximal responses were analyzed and expressed as $\mathrm{pD}_{2}$ $\left(-\log \mathrm{EC}_{50}\right.$ ) and Emax (maximum effect elicited by the agonist), respectively.

\section{Histological Analysis}

Thoracic aortas were fixed in phosphate buffered formaldehyde solution for $48 \mathrm{~h}$ and then dehydrated in ascending concentrations (70, 80, and 90\% and absolute I, II, and III) of ethyl alcohol, followed by diaphanization in xylol I, II, and III, and embedded in paraffin. $5 \mu \mathrm{m}$ transversal sections were stained by hematoxylin-eosin for morphological analysis or picrosirius for quantification of collagen fibers. The area of the middle layer and the PVAT were quantified surrounding the region occupied by the middle layer in the thoracic aorta or the fractions of adipose tissue located around the adventitia, respectively, in a Leica microscope coupled to a Quantimet 500 image analysis system (Leica, Bannockburn, IL) using a $\times 5$ lens magnification under a common light. Picrosirius-stained sections were examined in the same image analysis system aforementioned using $\mathrm{a} \times 20$ lens magnification. The area occupied by collagen was quantified by the color-detecting mode of the computer program in the adventitia. The aspect of collagen 

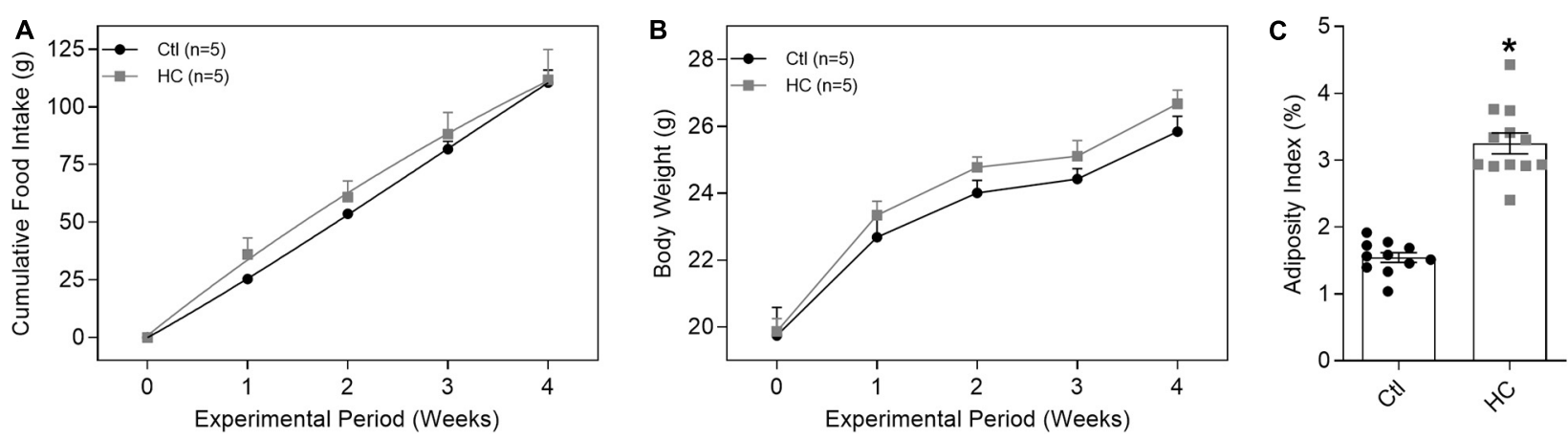

FIGURE 1 | Evaluation of (A) cumulative food intake, (B) body weight, and (C) adiposity index of mice fed standard or HC diets. Values represent mean \pm SEM. The total number of animals required to carry out the experiments in each group $(n)$ is presented in parentheses or in the dispersion points in the graphs. Statistical significance was determined using (A,B) two-way ANOVA followed by Holm-Sidak's post hoc test or (C) Student's $t$-test. * $p<0.05$ vs. control.

fibers was evaluated under a polarized light, allowing evaluation of the molecular disposition of collagen fibers (Borges et al., 2007; de Figueiredo Borges et al., 2008).

\section{Immunostaining of Mas and $\mathrm{AT}_{2}$ Receptors and the Isoforms of Nitric Oxide Synthase}

Frozen thoracic aortas of control and HC groups were serially cut in $10 \mu \mathrm{m}$ transversal sections, fixed in cold $100 \%$ acetone and washed with phosphate buffered saline (PBS). The fixed cryosections were rinsed in wash buffer $(4 \% \mathrm{BSA}+0.1 \%$ Triton $\mathrm{X}-100$, in PBS). Following appropriate blocking procedures (3\% BSA in PBS), the slides were incubated overnight at $4^{\circ} \mathrm{C}$ with rabbit monoclonal anti-Mas (Alomone Labs Cat\# AAR-013, RRID:AB_2039972), rabbit anti-AT 2 (Alomone Labs Cat\# AAR-012-AG, RRID:AB_2039724), mouse anti-eNOS (Santa Cruz Biotechnology Cat\# sc-136977, RRID:AB_2267282), mouse anti-iNOS (Santa Cruz Biotechnology Cat\# sc7271, RRID:AB_627810), mouse anti-nNOS (Santa Cruz Biotechnology Cat\# sc-5302, RRID:AB_626757), followed by incubation with goat anti-mouse secondary antibody conjugated with Alexa Fluor 488 (Santa Cruz Biotechnology Cat\# sc-362257, RRID:AB_10989084) and goat anti-rabbit secondary antibody conjugated with Alexa Fluor 594 (Thermo Fisher Scientific Cat\# A-11037, RRID:AB_2534095). The sections were examined under Nikon Eclipse Ti microscope (Nikon, United States) with excitation at $488 / 594 \mathrm{~nm}$ and emission at 520/600 $\mathrm{nm}$. The fluorescence intensity emitted was measured in different fields with the same area and analysis parameters only in the PVAT of the control and $\mathrm{HC}$ groups using Image ${ }^{\circledR}$ software $(\mathrm{NIH}$, Bethesda, MD, United States) and expressed as fold increase (Navia-Pelaez et al., 2017).

\section{Determination of Basal Nitric Oxide and Hydrogen Peroxide Availability}

Fluorescent probes 4-amino-5-methylamino- $2^{\prime}, 7^{\prime}$-difluorescein diacetate (DAF-2DA) and $2^{\prime}, 7^{\prime}$-dichlorodihydrofluorescein diacetate (DCF-DA) were used to measure $\mathrm{NO}$ and $\mathrm{H}_{2} \mathrm{O}_{2}$ in situ, respectively, in the PVAT of the control and $\mathrm{HC}$ groups. For that, thoracic aortas with intact PVAT of both experimental groups were embedded in freezing medium (Tissue-Tek, Sakura Finetek, Torrance, CA, United States). Transversal sections (10 $\mu \mathrm{m}$ thick) of frozen thoracic aortas were incubated with DAF-2DA $(2.5 \mu \mathrm{mol} / \mathrm{L})$ or DCF-DA $(2.5 \mu \mathrm{mol} / \mathrm{L})$ at $37^{\circ} \mathrm{C}$, protected from light. The images were captured on a Zeiss Axio Imager A2 fluorescence microscope where DAF-2DA was excited at $488 / 519 \mathrm{~nm}$, and DCF-DA was excited at a 590/618 nm. The fluorescence intensity emitted was measured in different fields with the same area and analysis parameters only in the PVAT of the control and HC groups using Image ${ }^{\circledR}$ software $(\mathrm{NIH}$, Bethesda, MD, United States) and expressed as fold increase (Campos-Mota et al., 2017).

\section{Statistical Analysis}

Graphs and analysis were blinded performed in the GraphPad Prism version 8 (GraphPad Software, San Diego, CA, United States). Determinations of $\mathrm{EC}_{50}$ and Emax were performed using the non-linear regression method of least squares (Meddings et al., 1989). The concentration values that produced half maximal contraction amplitude, which was determined after log transformation of the normalized concentration-response curves, were reported as negative logarithm $\left(\mathrm{pD}_{2}\right)$. The Emax values were considered as the maximal amplitude response reached in the concentrationresponse curves. Results were presented as standard mean \pm error (SEM). After checking adherence to the normal distribution, statistical significance was determined using Student's $t$-test for two group's comparison or two-way analysis of variance (ANOVA) for multiple group comparisons as appropriate, followed by Holm-Sidak's post hoc test. A value of $p<0.05$ was considered statistically significant.

\section{Materials}

The drugs phenylephrine (PE), captopril, A779, PD123,319, LY-294,002, N $\omega$-Nitro- L-arginine methyl ester hydrochloride (L-NAME), N $\omega$-Nitro-L-arginine (L-NNA), 1,400 W, 7Nitroindazole (7-Ni), catalase and tetraethylammonium (TEA) were purchased from Sigma-Aldrich (St. Louis, MO, 
TABLE 1 | Body weight and epididymal (EAT), retroperitoneal (RAT), and mesenteric (MAT) adipose tissues values of control and HC groups.

\begin{tabular}{|c|c|c|c|c|c|c|c|}
\hline Groups & Initial weight (g) & Final weight (g) & $n$ & EAT (g) & RAT (g) & MAT (g) & $n$ \\
\hline Control & $19.74 \pm 0.84$ & $25.84 \pm 0.45$ & 5 & $0.283 \pm 0.012$ & $0.052 \pm 0.004$ & $0.114 \pm 0.010$ & 11 \\
\hline $\mathrm{HC}$ & $19.87 \pm 0.38$ & $26.67 \pm 0.40$ & 5 & $0.566 \pm 0.031^{*}$ & $0.143 \pm 0.009^{*}$ & $0.252 \pm 0.018^{\star}$ & 12 \\
\hline
\end{tabular}

Values represent mean \pm SEM. Statistical significance was determined using Student's t-test. ${ }^{*} p<0.05$ vs. control.

United States). DAF-2DA and DCF-DA fluorescent probes were obtained from Invitrogen (Carlsbad, CA, United States).

\section{RESULTS}

\section{Food Consumption, Body Weight, and Adiposity Index}

Despite no change in cumulative food intake (Figure 1A) and body weight (Figure 1B and Table 1), mice fed HC diet exhibited considerable increase in visceral adiposity (Figure 1C and Table 1).

\section{Vascular Morphology and Collagen Evaluation}

To verify whether HC diet induced an increase in the PVAT area, morphological analysis was performed. We verified in Figures 2A,B,D a significant increase in the area occupied by PVAT in the HC group when compared to the control group. No significant changes were verified in the middle layer area between the groups (Figures $2 \mathrm{~A}-\mathrm{C}$ ).

Figure 2E shows the normal distribution of collagen fibers under the incidence of normal polychromatic light in the aorta of the control group. When evaluated under the incidence of polarized light, which allows analyzing the arrangement of the collagen fibers, Figure 2G shows that the collagen fibers were highly organized, exhibiting reddish color. Note the abundance of these fibers in adventitious layer (arrow). The same distribution and organization of the collagen fibers were observed in the aorta of the HC group (Figures $\mathbf{2 F}, \mathbf{H}$ ). Therefore, the HC diet did not induce vascular fibrosis, since no increase in the percentage of collagen fibers in the aorta of the HC group was found when compared to the control group (Figure 2I).

\section{Vascular Relaxation Induced by ACh}

The endothelium-dependent vasodilation induced by ACh in the control group was similar in the presence or absence of PVAT (Figure 3A). The same result was found in the HC group (Figure 3B). The overlapping curves showed that the $\mathrm{HC}$ diet did not induce endothelial dysfunction when compared to the control group (Figure $3 \mathrm{C}$ ). The Emax and $\mathrm{pD}_{2}$ values can be visualized in Table 2.

\section{Vascular Contraction Induced by PE}

In Figure 4A, the presence of PVAT did not alter the vasoconstrictor response induced by $\mathrm{PE}$ in aortas of the control group. However, after $\mathrm{HC}$ diet for 4 weeks, the presence of PVAT significantly attenuated PE-induced vasoconstriction (Figure 4B). The overlapping curves showed that, in the absence of PVAT, the vasoconstriction induced by PE was similar between both groups. Only in the presence of PVAT the contractile response induced by $\mathrm{PE}$ was significantly reduced in the $\mathrm{HC}$ group (Figure 4C).

Once the $\mathrm{HC}$ diet attenuated the vascular contraction induced by $\mathrm{PE}$ only in the presence of PVAT, the next experiments were performed in aortas with intact PVAT in order to identify the mechanisms underlying the anticontractile effect induced by HC diet. All the Emax and $\mathrm{pD}_{2}$ values can be visualized in Table 3 .

\section{Involvement of Renin-Angiotensin System}

As shown in Figure $\mathbf{5 A}$, the anticontractile effect of PVAT induced by $\mathrm{HC}$ diet was lost when aortic rings were previously incubated with the angiotensin converting enzyme (ACE) inhibitor, captopril. In addition, we verified the involvement of RAS receptors in this anticontractile effect of PVAT. The antagonism of Mas (Figure 5B) and $\mathrm{AT}_{2}$ (Figure 5C) receptors with A779 and PD123,319, respectively, also reestablished the contractile response induced by $\mathrm{PE}$ in the $\mathrm{HC}$ group to the level found in the control group.

\section{Immunolocalization of Mas and $\mathbf{A T}_{2}$ Receptors}

Since the activation of Mas and $\mathrm{AT}_{2}$ receptors was associated with the anticontractile effect of PVAT induced by $\mathrm{HC}$ diet, we further investigated if $\mathrm{Mas}$ and $\mathrm{AT}_{2}$ receptors were expressed in the PVAT of control and $\mathrm{HC}$ groups. Immunofluorescence assays allowed to evaluate whether PVAT express the antigen of Mas and $\mathrm{AT}_{2}$ receptors. The results demonstrated the presence of Mas (Figures 6B,E) and $\mathrm{AT}_{2}$ (Figures 6I,L) receptors in the PVAT of animals fed standard or HC diet. However, the fluorescence intensity was markedly higher in the PVAT of the $\mathrm{HC}$ group when compared to the control group as shown in Figures 6G,N.

\section{Involvement of the PI3k-Akt-NOS Pathway and Evaluation of Basal NO Availability}

As the activation of $\mathrm{Mas}$ and $\mathrm{AT}_{2}$ receptors can trigger the intracellular signaling cascade that activates PI3K-Akt pathway, we verified whether this pathway participates in the effect of $\mathrm{HC}$ diet on the control of vascular tone induced by PVAT. The inhibition of PI3K with LY294,002 reestablished the contractile response induced by $\mathrm{PE}$ in the $\mathrm{HC}$ group (Figure 7A). Knowing that the activation of PI3K-Akt pathway 

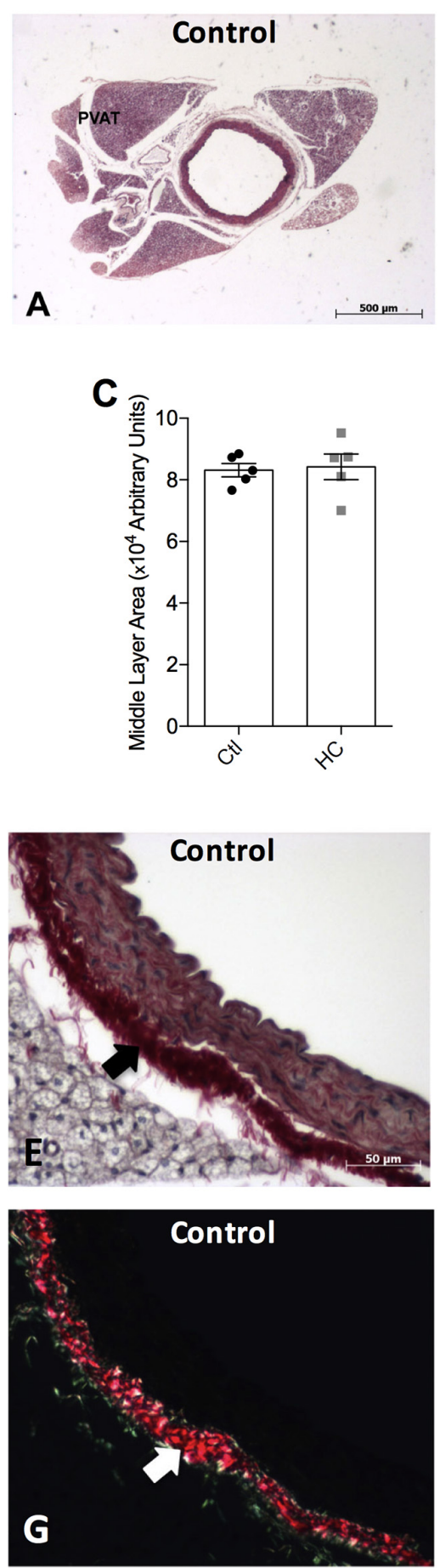
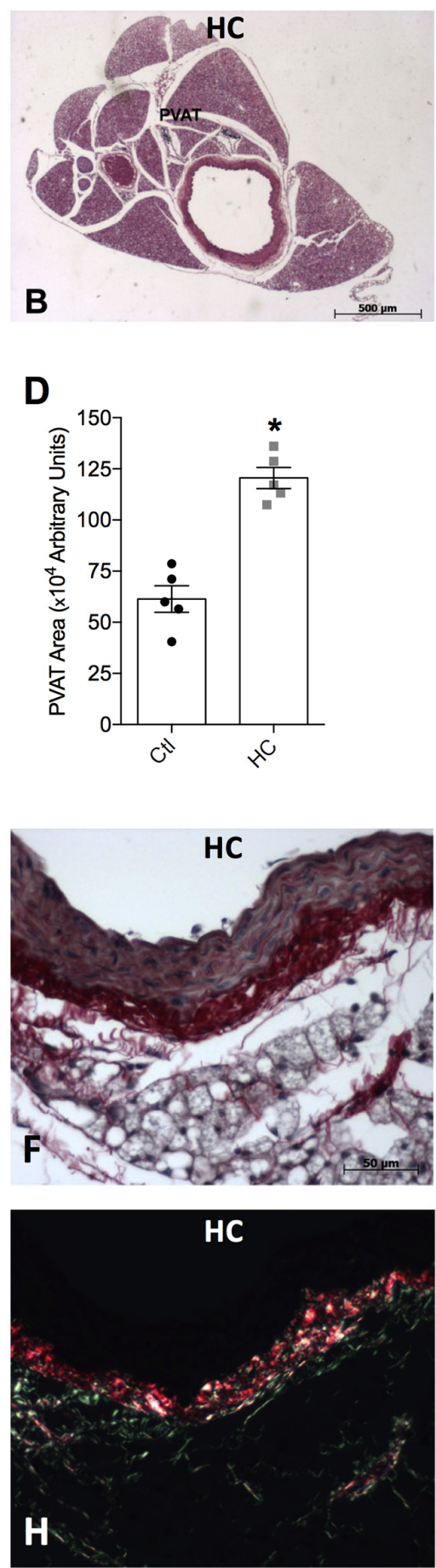

FIGURE 2 | Histological analysis of thoracic aorta and PVAT of control and HC groups. Representative histological sections stained by (A,B) hematoxylin-eosin, or picrosirius under the incidence of (E,F) normal polychromatic light or (G,H) polarized light. The areas of (C) middle layer or (D) PVAT, and (I) the percentage of collagen fibers are represented in graphical bars with mean \pm SEM. The total number of animals required to carry out the experiments in each group ( $n$ ) is presented in the dispersion points in the graphs. Statistical significance was determined using Student's $t$-test. ${ }^{\star} p<0.05$ vs. control. Arrows indicate the abundance of collagen fibers in the adventitious layer of blood vessels. Scale bars indicate (A,B) $500 \mu \mathrm{m}$ or (E-H) $50 \mu \mathrm{m}$.

can lead to NOS phosphorylation, we evaluated the involvement of NOS in the anticontractile effect of PVAT induced by HC diet. As shown in Figure $\mathbf{7 B}$, the non-selective inhibition of NOS with L-NAME reestablished the contractile response induced by $\mathrm{PE}$ in the $\mathrm{HC}$ group. Also, we verified in Figures 7C-E that basal $\mathrm{NO}$ availability was significantly 

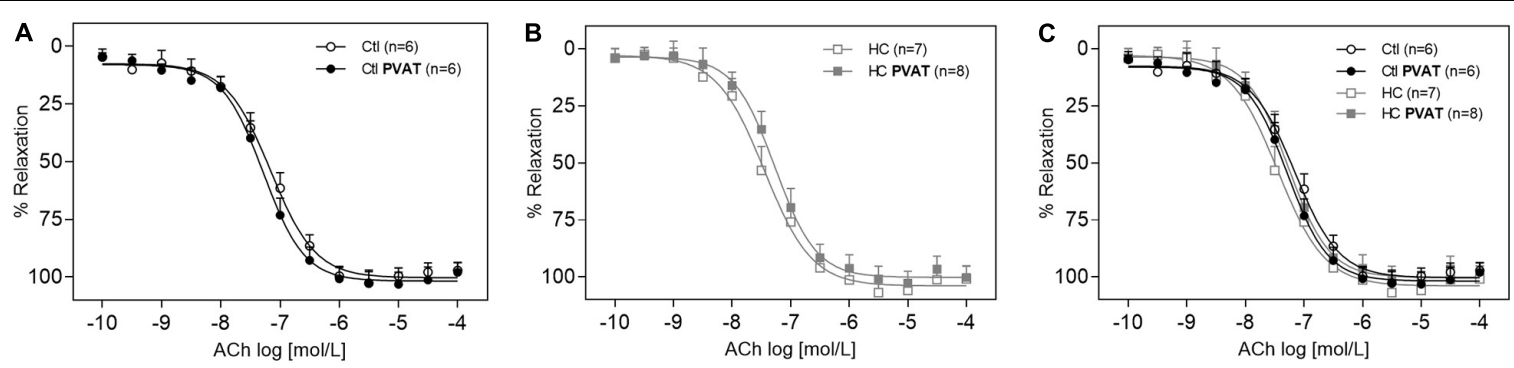

FIGURE 3 | Vasodilator response induced by ACh in the presence or absence of PVAT in aortas of control and HC groups. Cumulative concentration-response curves for ACh in the presence or absence of PVAT in aortas of (A) control, (B) HC, and (C) overlapping curves of control and HC groups. Values represent mean \pm SEM. The total number of animals required to carry out the experiments in each group $(n)$ is presented in parentheses in the graphs. Statistical significance was determined using two-way ANOVA followed by Holm-Sidak's post hoc test.

TABLE 2 | Emax and $\mathrm{pD}_{2}$ values of vascular relaxation induced by $\mathrm{ACh}$ in intact thoracic aortas in the presence or absence of PVAT.

\begin{tabular}{lrcr}
\hline Groups & \multicolumn{1}{c}{ Emax $(\mathbf{m N})$} & $\mathbf{p D}_{\mathbf{2}}\left(-\log \mathbf{E C}_{\mathbf{5 0}}\right)$ & $\boldsymbol{n}$ \\
\hline Control & $97.11 \pm 3.34$ & $7.14 \pm 0.09$ & 6 \\
HC & $100.84 \pm 5.50$ & $7.54 \pm 0.16$ & 7 \\
Control PVAT & $97.98 \pm 4.13$ & $7.28 \pm 0.07$ & 6 \\
HC PVAT & $100.17 \pm 5.04$ & $7.32 \pm 0.16$ & 8 \\
\hline
\end{tabular}

Values represent mean \pm SEM. Statistical significance was determined using twoway ANOVA followed by Holm-Sidak's post hoc test.

higher in the PVAT from HC group when compared to the control group.

\section{Contribution of the Endothelial (eNOS), Inducible (iNOS), and Neuronal (nNOS) Isoforms of NOS}

Once the involvement of NOS was confirmed, as well as an increase in basal levels of $\mathrm{NO}$, we further investigated which NOS isoforms would be related to the anticontractile effect of PVAT induced by HC diet. The inhibition of eNOS with L-NNA was not able to reverse the contractile response induced by $\mathrm{PE}$ in the HC group (Figure 8A). The iNOS inhibition with $1,400 \mathrm{~W}$ reestablished the Emax of contractile response induced by $\mathrm{PE}$ in the $\mathrm{HC}$ group, but the difference in $\mathrm{pD}_{2}$ values between both groups implies that the reversal of contractile response was only partial (Figure $\mathbf{8 B}$ and Table 3). However, the nNOS inhibition with $7 \mathrm{Ni}$ completely reestablished the contractile response induced by $\mathrm{PE}$ in the $\mathrm{HC}$ group (Figure 8C).

\section{Immunolocalization of eNOS, iNOS, and nNOS}

To verify whether or not PVAT express the antigen of NOS isoforms in the PVAT of control and HC groups, immunofluorescence assays were performed and revealed the presence of eNOS (Figures 9B,E), iNOS (Figures 9I,L), and nNOS (Figures 9P,S) in the PVAT of animals fed standard or HC diet. As shown in Figure 9G, the fluorescence intensity for eNOS was similar between both groups. However, the fluorescence intensity for iNOS (Figure 9N) and nNOS (Figure 9U) were markedly higher in the PVAT of the HC group. These findings were in agreement with the results found in vascular reactivity experiments, since only iNOS and nNOS isorforms were involved in the anticontractile effect of PVAT induced by $\mathrm{HC}$ diet.

\section{Contribution of $\mathrm{H}_{2} \mathrm{O}_{2}$ and Potassium Channels}

Once we found that nNOS is the main isoform involved in the anticontractile effect of PVAT induced by $\mathrm{HC}$ diet, and as this isoform not only produces $\mathrm{NO}$ but also $\mathrm{H}_{2} \mathrm{O}_{2}$, we verified the involvement of $\mathrm{H}_{2} \mathrm{O}_{2}$, another potent vasodilator factor. The degradation of $\mathrm{H}_{2} \mathrm{O}_{2}$ with catalase reestablished the contractile response induced by $\mathrm{PE}$ in $\mathrm{HC}$ group (Figure 10A). As shown in Figures 10B-D, basal $\mathrm{H}_{2} \mathrm{O}_{2}$ availability was significantly higher in the PVAT from $\mathrm{HC}$ group when compared to the control group.

Also, to investigate if the vasodilator response induced by NO and $\mathrm{H}_{2} \mathrm{O}_{2}$ in the $\mathrm{HC}$ group involves hyperpolarization through the opening of potassium channels, aortic rings were previously incubated with TEA. The non-selective blockade of potassium channels with TEA reestablished the Emax of contractile response induced by $\mathrm{PE}$ in the $\mathrm{HC}$ group, but the difference in $\mathrm{pD}_{2}$ values between both groups implies that the reversal of contractile response was only partial (Figure 10E and Table 3 ).

\section{DISCUSSION}

Excessive consumption of high caloric density food, rich in lipids and refined carbohydrates, is largely responsible for the obesity epidemic associated with health complications including cardiovascular disease and metabolic syndrome (Azevedo and Brito, 2012; Ferreira et al., 2014). Indeed, our findings showed that mice fed a high-refined carbohydrate diet significantly increased visceral adiposity, despite the unchanged food intake and body weight. Similarly, Oliveira et al. (2013) showed that HC diet promotes rapid and sustained increase of visceral adiposity, perceptible from 1 day of diet and maintained for up to 12 weeks, even though the similarity in the food intake and body weight compared to mice that received a standard 

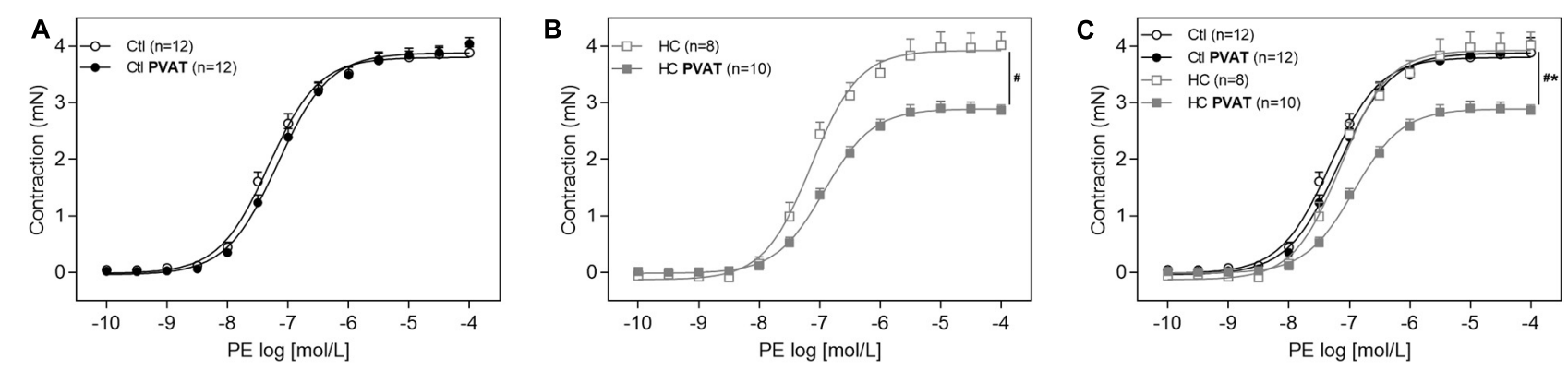

FIGURE 4 | Contractile response induced by PE in the presence or absence of PVAT in aortas of control and $\mathrm{HC}$ groups. Cumulative concentration-response curves for PE in the presence or absence of PVAT in aortas of (A) control, (B) HC, and (C) overlapping curves of control and HC groups. Values represent mean \pm SEM. The total number of animals required to carry out the experiments in each group $(n)$ is presented in parentheses in the graphs. Statistical significance was determined using two-way ANOVA followed by Holm-Sidak's post hoc test. ${ }^{\star} p<0.05$ vs. control PVAT; \#p < 0.05 vs. HC PVAT represent the differences in the Emax values.

TABLE 3 | Emax and $\mathrm{pD}_{2}$ values of vascular contraction induced by $P E$ in intact thoracic aortas in the presence or absence of PVAT, previously incubated or not with the specified drugs.

\begin{tabular}{|c|c|c|c|}
\hline Groups & $\operatorname{Emax}(\mathrm{mN})$ & $\mathrm{pD}_{2}\left(-\log \mathrm{EC}_{50}\right)$ & $n$ \\
\hline Control & $3.88 \pm 0.10$ & $7.18 \pm 0.06$ & 12 \\
\hline $\mathrm{HC}$ & $4.02 \pm 0.22^{\#}$ & $7.18 \pm 0.12$ & 8 \\
\hline Control PVAT & $4.04 \pm 0.11$ & $7.00 \pm 0.07$ & 12 \\
\hline HC PVAT & $2.86 \pm 0.09^{\star}$ & $6.94 \pm 0.06$ & 10 \\
\hline Control PVAT Captopril & $3.68 \pm 0.22$ & $7.32 \pm 0.09$ & 7 \\
\hline HC PVAT Captopril & $3.67 \pm 0.16^{\#}$ & $7.20 \pm 0.09$ & 5 \\
\hline Control PVAT A779 & $3.85 \pm 0.17$ & $7.52 \pm 0.05^{\star}$ & 8 \\
\hline HC PVAT A779 & $4.07 \pm 0.10^{\#}$ & $7.44 \pm 0.11^{\#}$ & 8 \\
\hline Control PVAT PD123,319 & $4.13 \pm 0.11$ & $7.42 \pm 0.04^{*}$ & 5 \\
\hline HC PVAT PD123,319 & $4.23 \pm 0.14^{\#}$ & $7.36 \pm 0.15^{\#}$ & 5 \\
\hline Control PVAT LY294,002 & $3.84 \pm 0.31$ & $7.20 \pm 0.17$ & 6 \\
\hline HC PVAT LY294,002 & $3.91 \pm 0.11^{\#}$ & $7.23 \pm 0.08$ & 10 \\
\hline Control PVAT L-NAME & $4.04 \pm 0.06$ & $7.66 \pm 0.07^{\star}$ & 6 \\
\hline HC PVAT L-NAME & $4.01 \pm 0.13^{\#}$ & $7.82 \pm 0.16^{\#}$ & 11 \\
\hline Control PVAT L-NNA & $3.82 \pm 0.10$ & $7.41 \pm 0.03^{\star}$ & 6 \\
\hline HC PVAT L-NNA & $3.10 \pm 0.09^{\star} \wedge$ & $7.13 \pm 0.05 \wedge$ & 6 \\
\hline Control PVAT 1,400 W & $4.04 \pm 0.13$ & $7.54 \pm 0.13^{\star}$ & 5 \\
\hline HC PVAT 1,400 W & $3.97 \pm 0.19^{\#}$ & $6.97 \pm 0.08 \wedge$ & 6 \\
\hline Control PVAT 7Ni & $4.16 \pm 0.23$ & $7.40 \pm 0.07^{\star}$ & 7 \\
\hline HC PVAT 7Ni & $4.19 \pm 0.19^{\#}$ & $7.26 \pm 0.09^{\#}$ & 8 \\
\hline Control PVAT Catalase & $3.92 \pm 0.09$ & $6.95 \pm 0.06$ & 5 \\
\hline HC PVAT Catalase & $3.86 \pm 0.11^{\#}$ & $7.02 \pm 0.05$ & 6 \\
\hline Control PVAT TEA & $3.72 \pm 0.13$ & $7.79 \pm 0.16^{\star}$ & 12 \\
\hline HC PVAT TEA & $3.68 \pm 0.07^{\#}$ & $7.14 \pm 0.10 \wedge$ & 6 \\
\hline
\end{tabular}

Values represent mean \pm SEM. Statistical significance was determined using twoway ANOVA followed by Holm-Sidak's post hoc test. " $p<0.05$ vs. control PVAT; $\# p<0.05$ vs. HC PVAT; $\wedge p<0.05$ vs. control PVAT L-NNA, 1,400 W or TEA.

diet (Oliveira et al., 2013). Herein, we showed that HC diet also increased the PVAT area.

The adipose tissue is deeply related to the cardiovascular system. The understanding of this relationship has been widely advanced from studies involving the influence of the PVAT on the vascular function, focusing on the identification of bioactive molecules released under physiological and pathological conditions ( $\mathrm{Gu}$ and $\mathrm{Xu}, 2013$ ). In the present study, we sought to investigate the effect of $\mathrm{HC}$ diet on the control of vascular tone induced by PVAT.

Our results showed that the known anticontractile effect of PVAT was not observed in the vascular contraction induced by $\mathrm{PE}$ in the control group. Although several studies have demonstrated that the PVAT classically attenuates the contractile responses under physiological conditions in different vascular beds in both rodents and humans (Soltis and Cassis, 1991; Lohn et al., 2002; Dubrovska et al., 2004; Gao et al., 2005, 2007), this effect was not visualized in intact endothelium thoracic aorta of Balb/c mice which could be a limitation of the strain used in the present study, so comparisons to other studies must be done with care. Recently, Nobrega et al. (2019) found that the anticontractile effect of PVAT in thoracic aortas from $\mathrm{Balb} / \mathrm{c}$ mice was only visualized in denuded endothelium aortas (Nobrega et al., 2019).

Interestingly, the $\mathrm{HC}$ diet significantly reduced the contractile response induced by $\mathrm{PE}$ only in the presence of PVAT, enhancing the anticontractile effect of PVAT once it was not observed in the control group as expected. These results corroborate those found in coronary arterioles of obese humans by Fulop et al. (2007), pioneers in suggesting that obesity may lead to the activation of adaptive vascular mechanisms to improve blood vessels function (Fulop et al., 2007). Moreover, our results showed that the HC diet did not induce endothelial dysfunction, since no impairment were found in endothelium-dependent vasodilation induced by ACh in the presence or absence of PVAT in the HC group when compared to the control group. However, our results differ from most studies that showed a vasoconstriction profile of PVAT and endothelial dysfunction during different dietsinduced obesity, enriched in lipids or fructose, culminating in the loss of the anticontractile effect of PVAT (Ketonen et al., 2010; Ma et al., 2010; Rebolledo et al., 2010; GilOrtega et al., 2014). This might be due to the type of diet and the longer period of dietary treatment used in these studies.

Histological analysis showed that the attenuation of vascular contractility in the $\mathrm{HC}$ group only visualized 

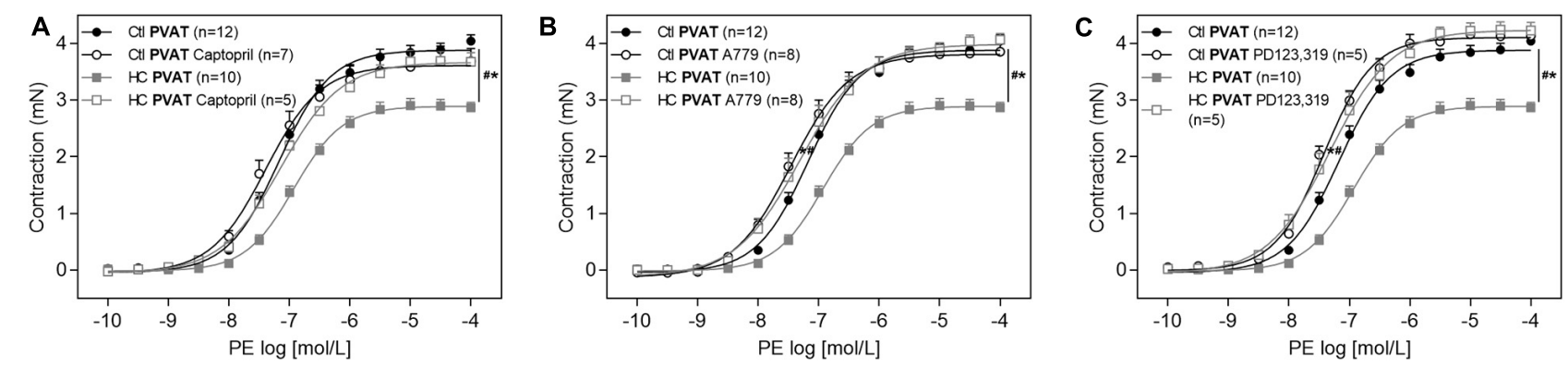

FIGURE 5 | Involvement of RAS in the effect of HC diet on the PVAT control of vascular tone. Cumulative concentration-response curves for PE in the presence of PVAT in aortas of control and HC groups previously incubated or not with (A) captopril, (B) A779, or (C) PD123,319. Values represent mean \pm SEM. The total number of animals required to carry out the experiments in each group $(n)$ is presented in parentheses in the graphs. Statistical significance was determined using two-way ANOVA followed by Holm-Sidak's post hoc test. ${ }^{*} p<0.05$ vs. control PVAT; $\# p<0.05$ vs. HC PVAT represent the differences in the Emax and pD 2 values.
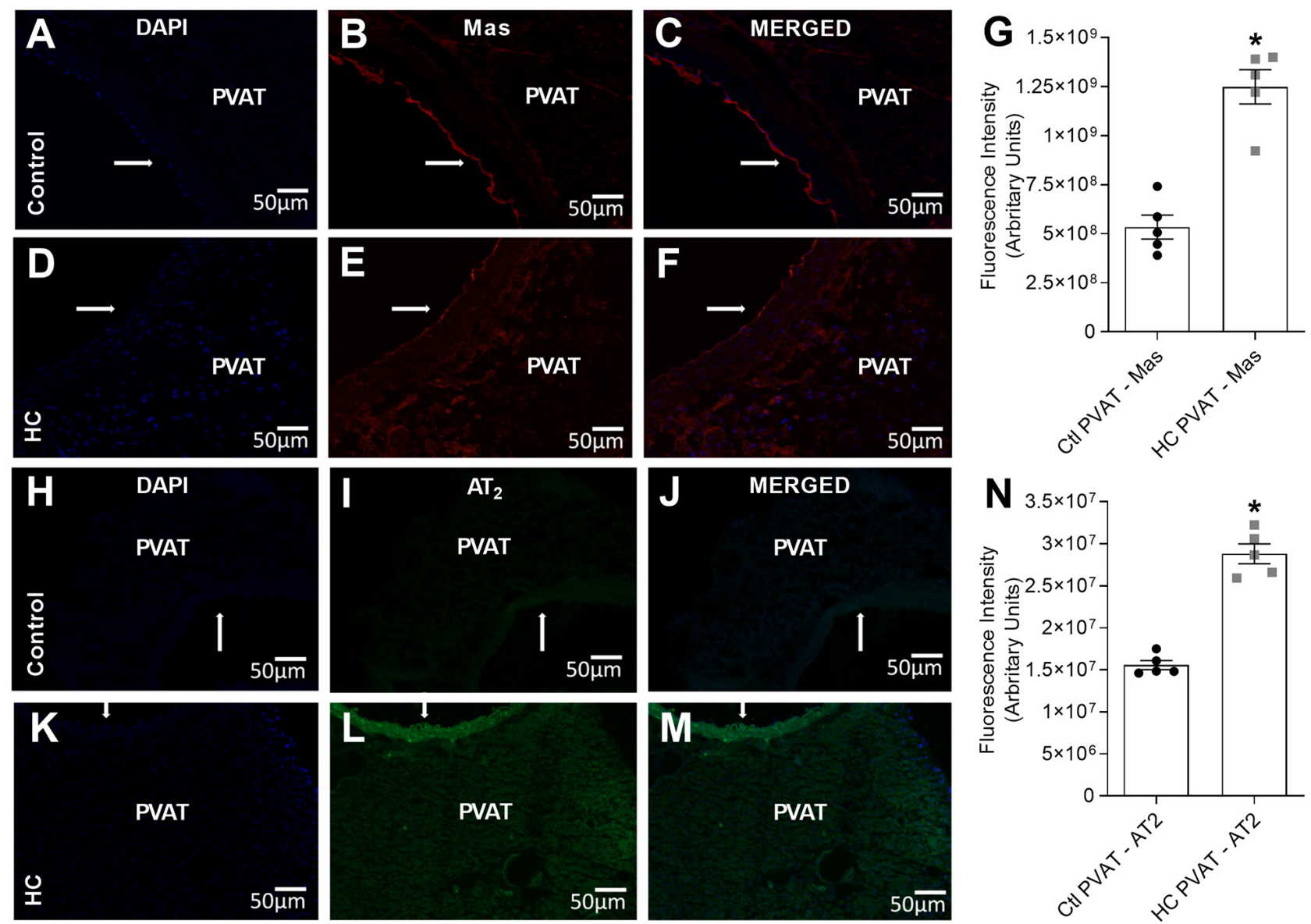

FIGURE 6 | Immunofluorescence of Mas and AT2 receptors in the PVAT of control and HC groups. (A,D,H,K) Nuclear immunostaining with DAPI. Immunostaining for (B,E) Mas or (I,L) AT 2 receptors. Overlap of immunostaining for $\mathbf{( C , F ) ~ M a s ~ r e c e p t o r s ~ a n d ~ D A P I ~ o r ~} \mathbf{( J , M ) ~ A T} 2$ receptors and DAPI. Fluorescence intensity emitted by binding the selective secondary antibody to (G) Mas (red fluorescence) or (N) $\mathrm{AT}_{2}$ (green fluorescence) receptors in the PVAT, respectively, were represented in graphical bars with mean \pm SEM. The total number of animals required to carry out the experiments in each group $(n)$ is presented in the dispersion points in the graphs. Statistical significance was determined using Student's $t$-test. ${ }^{*} p<0.05$ vs. control. Arrows indicate the location of the endothelial layer of blood vessels. Scale bars indicate $50 \mu \mathrm{m}$. 

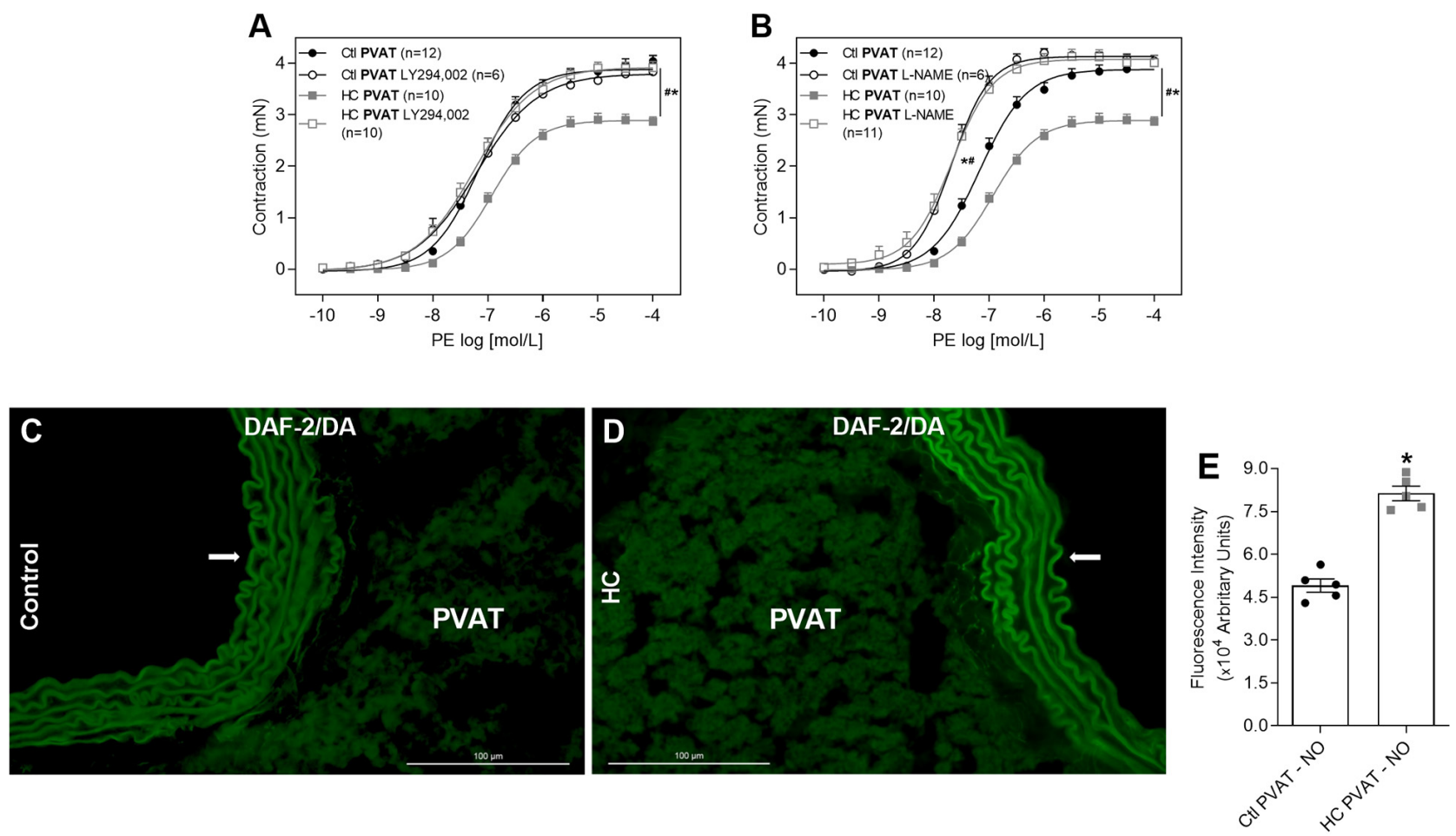

FIGURE 7 | Involvement of PI3K-Akt-NOS pathway in the effect of HC diet on PVAT control of vascular tone and evaluation of NO availability. Cumulative concentration-response curves for PE in the presence of PVAT in aortas of control and HC groups previously incubated or not with (A) LY294,002 or (B) L-NAME. Values represent mean $\pm \mathrm{SEM}$. The total number of animals required to carry out the experiments in each group $(n)$ is presented in parentheses. Statistical significance was determined using two-way ANOVA followed by Holm-Sidak's post hoc test. ${ }^{*} p<0.05$ vs. control PVAT; \#p $<0.05$ vs. HC PVAT represent the differences in the Emax and $\mathrm{pD}_{2}$ values. Representative sections of basal $\mathrm{NO}$ availability in the PVAT of (C) control and (D) HC groups exposed to DAF-2DA probe. Arrows indicate the location of the endothelial layer of blood vessels. Scale bars indicate $100 \mu \mathrm{m}$. (E) Quantification of NO production in the PVAT was expressed as fluorescence intensity in graphical bars with mean \pm SEM. The total number of animals required to carry out the experiments in each group $(n)$ is presented in the dispersion points in the graphs. Statistical significance was determined using Student's $t$-test. ${ }^{*} p<0.05$ vs. control.
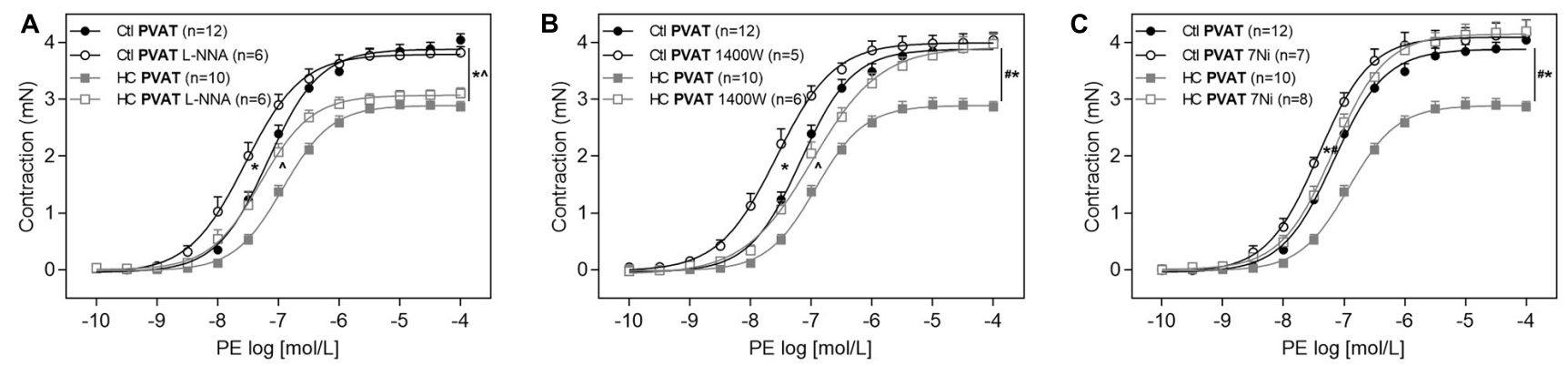

FIGURE 8 | Implication of eNOS, iNOS, and nNOS in the effect of HC diet on control of vascular tone induced by PVAT. Cumulative concentration-response curves for PE in the presence of PVAT in aortas of control and HC groups previously incubated or not with (A) L-NNA, (B) 1,400 W, or (C) $7 \mathrm{Ni}$. Values represent mean \pm SEM. The total number of animals required to carry out the experiments in each group $(n)$ is presented in parentheses in the graphs. Statistical significance was determined using two-way ANOVA followed by Holm-Sidak's post hoc test. ${ }^{*} p<0.05$ vs. control PVAT; $\# p<0.05$ vs. HC PVAT; $\wedge p<0.05$ vs. control PVAT L-NNA or 1,400 W represent the differences in the Emax and $\mathrm{pD}_{2}$ values.

in aortas with intact PVAT was not associated with a vascular fibrosis process. Therefore, we sought to investigate which factors could be responsible for enhancing the anticontractile effect of PVAT in the HC group.
The renin-angiotensin system (RAS) hyperactivity is one of the central mechanisms of cardiovascular diseases related to obesity (Rahmouni et al., 2005; Engeli, 2006). Several studies have been dedicated to investigate the local RAS, especially in the adipose tissue. Renin and all other components of the system 

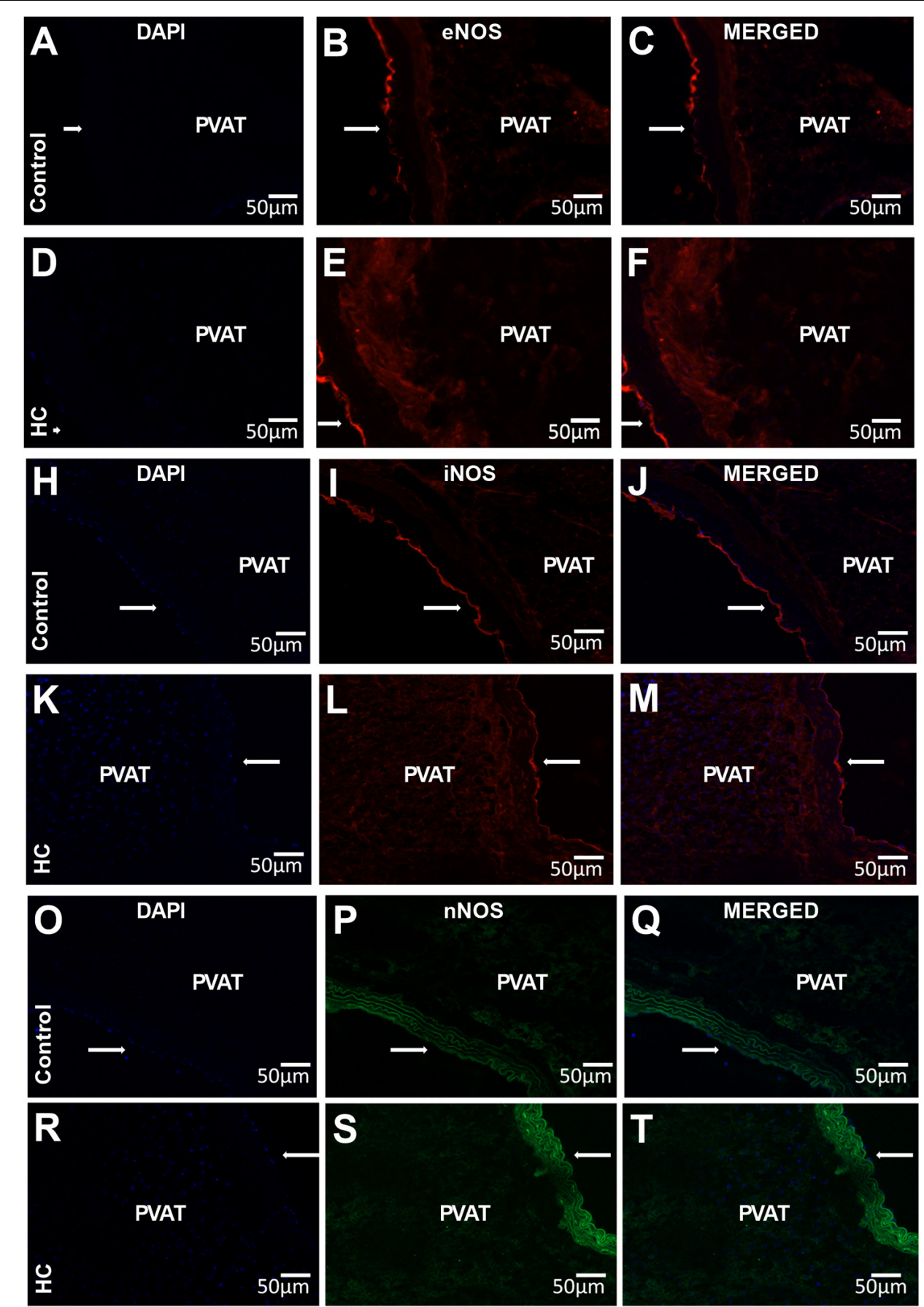
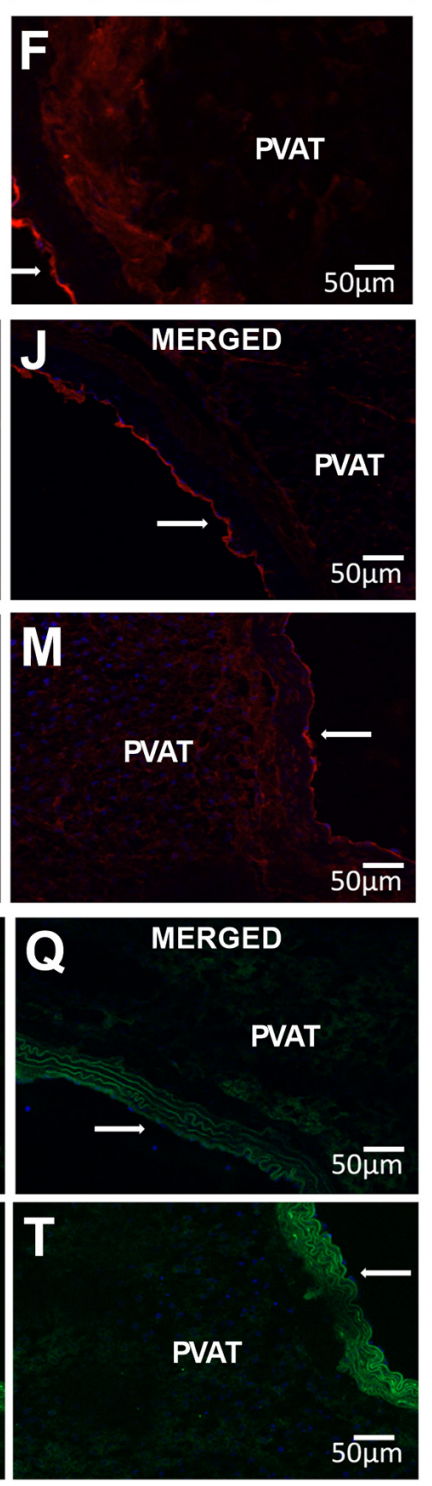
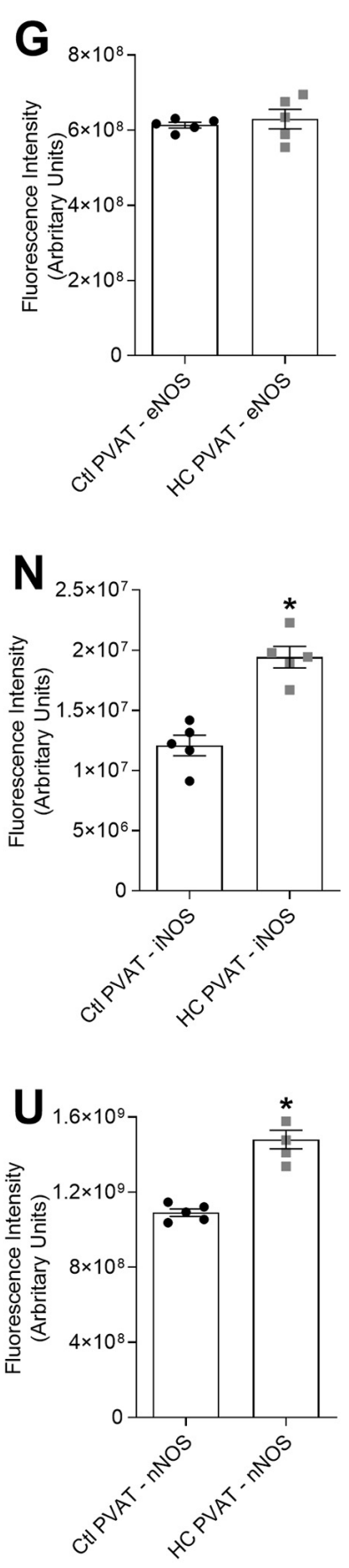

FIGURE 9 | Immunofluorescence of eNOS, iNOS and nNOS in the PVAT of control and HC groups. (A,D,H,K,O,R) Nuclear immunostaining with DAPI. Immunostaining for (B,E) eNOS, (I,L) iNOS or (P,S) nNOS. Overlap of immunostaining for (C,F) eNOS and DAPI, (J,M) iNOS and DAPI or (Q,T) nNOS and DAPI. Fluorescence intensity emitted by binding the selective secondary antibody to (G) eNOS (red fluorescence), (N) iNOS (red fluorescence), or (U) nNOS (green fluorescence) in the PVAT, respectively, were represented in graphical bars with mean \pm SEM. The total number of animals required to carry out the experiments in each group $(n)$ is presented in the dispersion points in the graphs. Statistical significance was determined using Student's $t$-test. ${ }^{*} p<0.05$ vs. control. Arrows indicate the location of the endothelial layer of blood vessels. Scale bars indicate $50 \mu \mathrm{m}$.

(angiotensinogen, renin-binding protein, ACE, and peptidergic receptors), were found in adipose tissue of rodents and humans (Engeli et al., 1999; Schling et al., 1999; Cassis, 2000).
Herein, our results showed the involvement of ACE and the activation of Mas and $\mathrm{AT}_{2}$ receptors in the anticontractile effect of PVAT induced by HC diet. While the majority of studies 

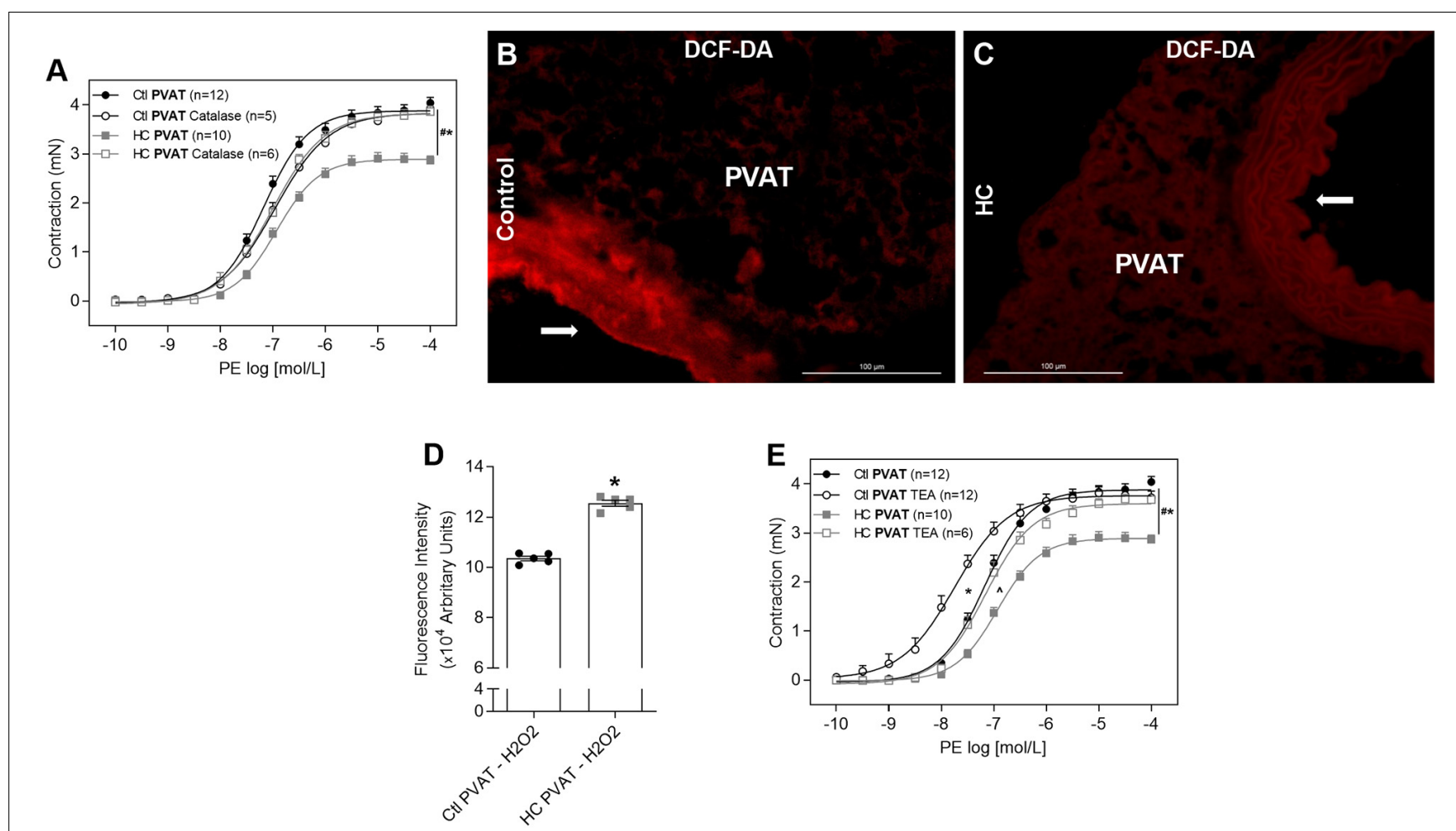

FIGURE 10 | Involvement of $\mathrm{H}_{2} \mathrm{O}_{2}$ and potassium channels in the effect of $\mathrm{HC}$ diet on PVAT control of vascular tone and evaluation of $\mathrm{H}_{2} \mathrm{O}_{2}$ availability. Cumulative concentration-response curves for PE in the presence of PVAT in aortas of control and HC groups previously incubated or not with (A) catalase or (E) TEA. Values represent mean \pm SEM. The total number of animals required to carry out the experiments in each group $(n)$ is presented in parentheses in the graphs. Statistical significance was determined using two-way ANOVA followed by Holm-Sidak's post hoc test. ${ }^{*} p<0.05$ vs. control PVAT; \#p < 0.05 vs. HC PVAT; $\wedge p<0.05$ vs. control PVAT TEA represent the differences in the Emax and $\mathrm{pD}_{2}$ values. Representative sections of basal $\mathrm{H}_{2} \mathrm{O}_{2}$ levels in the PVAT of (B) control and (C) $\mathrm{HC}$ groups exposed to DCF-DA probe. Arrows indicate the location of the endothelial layer of blood vessels. Scale bars indicate $100 \mu \mathrm{m}$. (D) $\mathrm{Quantification}$ of $\mathrm{H}_{2} \mathrm{O}_{2}$ production in the PVAT was expressed as fluorescence intensity in graphical bars with mean \pm SEM. The total number of animals required to carry out the experiments in each group $(n)$ is presented in the dispersion points in the graphs. Statistical significance was determined using Student's $t$-test. * $p<0.05$ vs. control.

address the effect of obesity associated with RAS hyperactivity through the ACE/Ang II/AT1 signaling pathway (Mathai et al., 2011), the ACE/Ang II/AT 2 or $\mathrm{ACE}_{2} / \mathrm{Ang} 1-7 / \mathrm{Mas} / \mathrm{AT}_{2}$ signaling pathways may be the key to elucidate the molecular mechanisms involved in protecting vascular homeostasis, especially during the development of pathological conditions such as obesity (Nguyen Dinh Cat and Touyz, 2011).

The literature has reported that activation of Mas and $\mathrm{AT}_{2}$ receptors can trigger the intracellular signaling cascade that activates the PI3K-Akt pathway (Sampaio et al., 2007; Wu et al., 2016). Also, in addition to the well-known activation of NOS by the calcium-calmodulin complex, alternative mechanisms of NOS activation have been proposed involving NOS phosphorylation through the PI3K-Akt signaling pathway (Fulton et al., 1999; Cunha et al., 2010). Therefore, we sought to investigate whether the components of this signaling pathway participated in the anticontractile effect of PVAT induced by $\mathrm{HC}$ diet. Our findings demonstrated that, besides the activation of Mas and $\mathrm{AT}_{2}$ receptors, the PI3K and NOS activation were also involved in the effect of HC diet on the control of vascular tone induced by PVAT, suggesting the activation of the signaling cascade triggered by RAS through the activation of Mas and $\mathrm{AT}_{2}$ receptors, PI3K-Akt and NOS in the anticontractile effect of PVAT induced by $\mathrm{HC}$ diet.

When we evaluated which NOS isoform was involved, our findings showed that the inhibition of eNOS did not reverse the effect of HC diet on the PVAT control of vascular tone. Only the inhibition of iNOS and nNOS isoforms partially and completely reestablished this effect, respectively. These results corroborated with the immunofluorescence assays that showed increased fluorescence intensity only of iNOS and nNOS isoforms in the PVAT of the HC group.

The iNOS isoform has been implicated in the pathogenesis of many diseases associated with inflammation, such as obesity (Fujimoto et al., 2005; Carvalho-Filho et al., 2009; Torrisi et al., 2016). In addition, recent studies have demonstrated that the PI3K/Akt pathway also leads to the activation of iNOS (Wang et al., 2015; Cianciulli et al., 2016). However, our results showed that the iNOS was partially involved in the anticontractile effect of PVAT induced by $\mathrm{HC}$ diet. The main isoform involved was the nNOS. Benkhoff et al. (2012) showed that aortic nNOS expression was increased in obese C57BL/6J mice fed a high-fat diet for 32 weeks (Benkhoff et al., 2012). Furthermore, the PI3K/Akt 


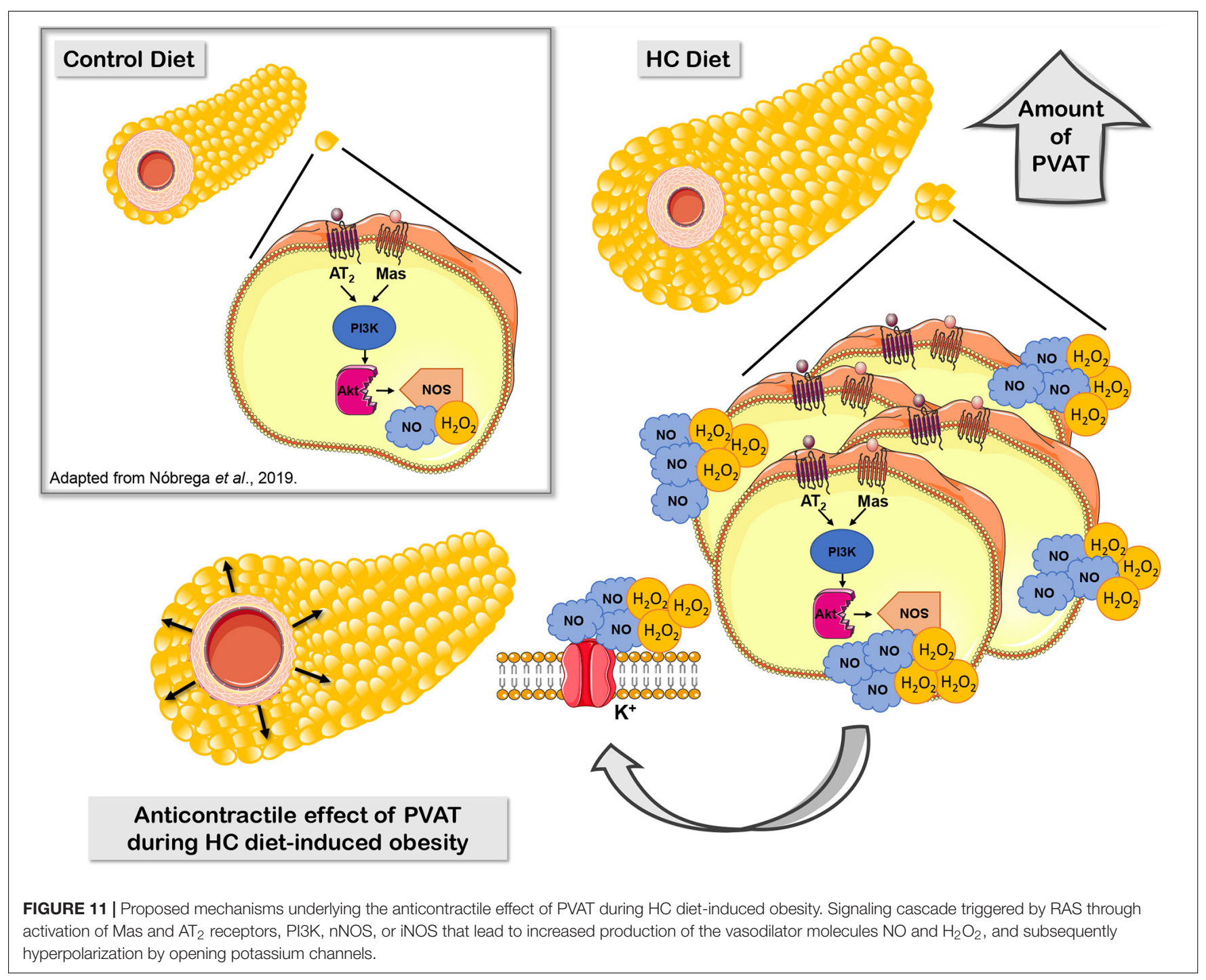

signaling pathway has also been shown to be involved in the activation of nNOS (El-Mas et al., 2009; Wu et al., 2016).

The nNOS not only produces $\mathrm{NO}$ but also $\mathrm{H}_{2} \mathrm{O}_{2}$, another potent vasodilator agent (Capettini et al., 2008). Our results showed the involvement of $\mathrm{H}_{2} \mathrm{O}_{2}$ in the anticontractile effect of PVAT induced by $\mathrm{HC}$ diet, with also increased basal levels of $\mathrm{NO}$ and $\mathrm{H}_{2} \mathrm{O}_{2}$ in the PVAT of the $\mathrm{HC}$ group. Both $\mathrm{NO}$ and $\mathrm{H}_{2} \mathrm{O}_{2}$ can induce vasodilator response in part through the opening of potassium channels (Barlow et al., 2000; Gao et al., 2003; Lee et al., 2009). We found that potassium channels were partially involved in the effect of $\mathrm{HC}$ diet on the control of vascular tone induced by PVAT. These findings suggest that, at least in part, $\mathrm{NO}$ and $\mathrm{H}_{2} \mathrm{O}_{2}$ could induce the anticontractile effect of PVAT in the HC group through the opening of potassium channels.

Our research group recently demonstrated that, under physiological conditions, the activation of Mas and $\mathrm{AT}_{2}$ receptors and the production of $\mathrm{H}_{2} \mathrm{O}_{2}$ and $\mathrm{NO}$ contribute to the anticontractile effect of PVAT only visualized in denuded endothelium aortas (Nobrega et al., 2019). In the present study, we proposed that the $\mathrm{HC}$ diet induces a significant increase in the PVAT area, which may correlates with an increased Mas and $\mathrm{AT}_{2}$ receptors and production of $\mathrm{NO}$ and $\mathrm{H}_{2} \mathrm{O}_{2}$ that enhanced the anticontractile effect of PVAT previously not observed in intact endothelium aortas from animals fed a standard diet (Figure 11).

In summary, our findings improve the understanding about the early effect of PVAT on the control of vascular tone in an obesity context. The HC diet for 4 weeks enhanced the release of vasodilators factors from PVAT, suggesting that this could be a compensatory adaptive characteristic in order to preserve the vascular function during initial steps of obesity. The mechanisms underlying the anticontractile effect of PVAT induced by HC diet may involve the signaling cascade triggered by RAS through the activation of Mas and $\mathrm{AT}_{2}$ receptors, $\mathrm{PI} 3 \mathrm{~K}, \mathrm{nNOS}$, and iNOS that lead to increased production of $\mathrm{NO}$ and $\mathrm{H}_{2} \mathrm{O}_{2}$, and subsequently opening of potassium channels. 


\section{DATA AVAILABILITY STATEMENT}

The original contributions presented in the study are included in the article/supplementary material, further inquiries can be directed to the corresponding author/s.

\section{ETHICS STATEMENT}

The animal study was reviewed and approved by Ethics Committee on Animal Use of Federal University of Minas Gerais under the protocol number 225/2013.

\section{AUTHOR CONTRIBUTIONS}

DR: conceptualization, methodology, investigation, formal analysis, and writing - original draft. AS and GC: methodology and formal analysis. NN and NA: validation, formal analysis, and writing - review and editing. LB, LC and AF: methodology, formal analysis, and resources. DB: conceptualization,

\section{REFERENCES}

Aghamohammadzadeh, R., Withers, S., Lynch, F., Greenstein, A., Malik, R., and Heagerty, A. (2012). Perivascular adipose tissue from human systemic and coronary vessels: the emergence of a new pharmacotherapeutic target. $\mathrm{Br}$. J. Pharmacol. 165, 670-682. doi: 10.1111/j.1476-5381.2011.01479.x

Araújo, A. V., Ferezin, C. Z., De Amanda, A., Rodrigues, G. J., Grando, M. D., Bonaventura, D., et al. (2012). Augmented nitric oxide production and upregulation of endothelial nitric oxide synthase during cecal ligation and perforation. Nitric Oxide Biol. Chem. 27, 59-66. doi: 10.1016/j.niox.2012.04.005

Azevedo, F. R., and Brito, B. C. (2012). Influence of nutritional variables and obesity on health and metabolism. Rev. Assoc. Med. Bras. 58, 714-723.

Babbedge, R. C., Bland-Ward, P. A., Hart, S. L., and Moore, P. K. (1993). Inhibition of rat cerebellar nitric oxide synthase by 7-nitro indazole and related substituted indazoles. Br. J. Pharmacol. 110, 225-228. doi: 10.1111/j.1476-5381. 1993.tb13796.x

Bader, M., Alenina, N., Andrade-Navarro, M. A., and Santos, R. A. (2014). MAS and its related G protein-coupled receptors, Mrgprs. Pharmacol. Rev. 66, 1080-1105. doi: 10.1124/pr.113.008136

Barlow, R. S., El-Mowafy, A. M., and White, R. E. (2000). H(2)O(2) opens BK(Ca) channels via the PLA(2)-arachidonic acid signaling cascade in coronary artery smooth muscle. Am. J. Physiol. Hear. Circ. Physiol. 279, H475-H483.

Benkhoff, S., Loot, A. E., Pierson, I., Sturza, A., Kohlstedt, K., Fleming, I., et al. (2012). Leptin potentiates endothelium-dependent relaxation by inducing endothelial expression of neuronal NO synthase. Arterioscler. Thromb. Vasc. Biol. 32, 1605-1612. doi: 10.1161/ATVBAHA.112.251140

Bonaventura, D., De Lima, R. G., Da Silva, R. S., and Bendhack, L. M. (2011). NO donors-relaxation is impaired in aorta from hypertensive rats due to a reduced involvement of $\mathrm{K}+$ channels and sarcoplasmic reticulum $\mathrm{Ca} 2+-\mathrm{ATPase}$. Life Sci. 89, 595-602. doi: 10.1016/j.lfs.2011.07.022

Borges, L. F., Gutierrez, P. S., Marana, H. R. C., and Taboga, S. R. (2007). Picrosirius-polarization staining method as an efficient histopathological tool for collagenolysis detection in vesical prolapse lesions. Micron 38, 580-583. doi: 10.1016/j.micron.2006.10.005

Britton, K. A., and Fox, C. S. (2011). Perivascular adipose tissue and vascular disease. Clin. Lipidol. 6, 79-91. doi: 10.2217/clp.10.89

Brown, N. K., Zhou, Z., Zhang, J., Zeng, R., Wu, J., Eitzman, D. T., et al. (2014). Perivascular adipose tissue in vascular function and disease: a review of current research and animal models. Arterioscler. Thromb. Vasc. Biol. 34, 1621-1630. doi: 10.1161/ATVBAHA.114.303029

Campos-Mota, G. P., Navia-Pelaez, J. M., Araujo-Souza, J. C., Stergiopulos, N., and Capettini, L. S. A. (2017). Role of ERK1/2 activation and nNOS uncoupling supervision, resources, funding acquisition, and writing - review and editing. All authors contributed to the article and approved the submitted version.

\section{FUNDING}

This work was supported by grants from Fundação de Amparo à Pesquisa do Estado de Minas Gerais (FAPEMIG), Coordenação de Aperfeiçoamento de Pessoal de Nível Superior (CAPES), and Conselho Nacional de Desenvolvimento Científico e Tecnológico (CNPq).

\section{ACKNOWLEDGMENTS}

We would like to thank funding support from FAPEMIG, CAPES, and CNPq. The supervision and technical assistance of Helton José dos Reis research group had provided help with fluorescence microscopy analysis.

on endothelial dysfunction induced by lysophosphatidylcholine. Atherosclerosis 258, 108-118. doi: 10.1016/j.atherosclerosis.2016.11.022

Capettini, L. S. A., Cortes, S. F., Gomes, M. A., Silva, G. A. B., Pesquero, J. L., Lopes, M. J., et al. (2008). Neuronal nitric oxide synthase-derived hydrogen peroxide is a major endothelium-dependent relaxing factor. Am. J. Physiol. Circ. Physiol. 295, H2503-H2511. doi: 10.1152/ajpheart.00731.2008

Carvalho-Filho, M. A., Ropelle, E. R., Pauli, R. J., Cintra, D. E., Tsukumo, D. M. L., Silveira, L. R., et al. (2009). Aspirin attenuates insulin resistance in muscle of diet-induced obese rats by inhibiting inducible nitric oxide synthase production and S-nitrosylation of IR $\beta /$ IRS-1 and Akt. Diabetologia 52, 2425-2434. doi: 10.1007/s00125-009-1498-91

Cassis, L. A. (2000). Fat cell metabolism: insulin, fatty acids, and renin. Curr. Hypertens. Rep. 2, 132-138. doi: 10.1007/s11906-000-0072-5

Castro, C. H., Santos, R. A., Ferreira, A. J., Bader, M., Alenina, N., and Almeida, A. P. (2005). Evidence for a functional interaction of the angiotensin-(1-7) receptor Mas with AT1 and AT2 receptors in the mouse heart. Hypertension 46, 937-942. doi: 10.1161/01.HYP.0000175813.04375.8a

Cianciulli, A., Calvello, R., Porro, C., Trotta, T., Salvatore, R., and Panaro, M. A. (2016). PI3k/Akt signalling pathway plays a crucial role in the anti-inflammatory effects of curcumin in LPS-activated microglia. Int. Immunopharmacol. 36, 282-290. doi: 10.1016/j.intimp.2016.05.007

Cunha, T. M., Roman-Campos, D., Lotufo, C. M., Duarte, H. L., Souza, G. R., Verri, W. A., et al. (2010). Morphine peripheral analgesia depends on activation of the PI3K /AKT/nNOS/NO/KATP signaling pathway. Proc. Natl. Acad. Sci. U.S.A. 107, 4442-4447. doi: 10.1073/pnas.0914733107

Dashwood, M. R., Dooley, A., Shi-Wen, X., Abraham, D. J., Dreifaldt, M., and Souza, D. S. R. (2011). Perivascular fat-derived leptin: a potential role in improved vein graft performance in coronary artery bypass surgery. Interact. Cardiovasc. Thorac. Surg. 12, 170-173. doi: 10.1510/icvts.2010.247874

de Figueiredo Borges, L., Jaldin, R. G., Dias, R. R., Stolf, N. A. G., Michel, J. B., and Gutierrez, P. S. (2008). Collagen is reduced and disrupted in human aneurysms and dissections of ascending aorta. Hum. Pathol. 39, 437-443. doi: 10.1016/j. humpath.2007.08.003

Dubrovska, G., Verlohren, S., Luft, F. C., and Gollasch, M. (2004). Mechanisms of ADRF release from rat aortic adventitial adipose tissue. Am. J. Physiol. Hear. Circ. Physiol. 286, H1107-H1113. doi: 10.1152/ajpheart.00656.2003

El-Mas, M. M., Fan, M., and Abdel-Rahman, A. A. (2009). Facilitation of myocardial PI3K/Akt/nNOS signaling contributes to ethanol-evoked hypotension in female rats. Alcohol. Clin. Exp. Res. 33, 1158-1168. doi: 10.1111/ j.1530-0277.2009.00939.x

Engeli, S. (2006). Role of the renin-angiotensin- aldosterone system in the metabolic syndrome. Contrib. Nephrol. 151, 122-134. doi: 10.1159/000095324 
Engeli, S., Gorzelniak, K., Kreutz, R., Runkel, N., Distler, A., and Sharma, A. M. (1999). Co-expression of renin-angiotensin system genes in human adipose tissue. J. Hypertens 17, 555-560. doi: 10.1097/00004872-199917040-00014

Faria-Costa, G., Leite-Moreira, A., and Henriques-Coelho, T. (2014). Cardiovascular effects of the angiotensin type 2 receptor. Rev. Port. Cardiol. 33, 439-449. doi: 10.1016/j.repc.2014.02.011

Ferreira, A. V., Mario, E. G., Porto, L. C., Andrade, S. P., and Botion, L. M. (2011). High-carbohydrate diet selectively induces tumor necrosis factor-alpha production in mice liver. Inflammation 34, 139-145. doi: 10.1007/s10753-0109217-0

Ferreira, A. V., Menezes-Garcia, Z., Viana, J. B., Mario, E. G., and Botion, L. M. (2014). Distinct metabolic pathways trigger adipocyte fat accumulation induced by high-carbohydrate and high-fat diets. Nutrition 30, 1138-1143. doi: 10.1016/ j.nut.2014.02.017

Fesus, G., Dubrovska, G., Gorzelniak, K., Kluge, R., Huang, Y., Luft, F. C., et al. (2007). Adiponectin is a novel humoral vasodilator. Cardiovasc. Res. 75, 719-727. doi: 10.1016/j.cardiores.2007.05.025

Flanagan, A. M., Brown, J. L., Santiago, C. A., Aad, P. Y., Spicer, L. J., and Spicer, M. T. (2008). High-fat diets promote insulin resistance through cytokine gene expression in growing female rats. J. Nutr. Biochem. 19, 505-513. doi: 10.1016/ j.jnutbio.2007.06.005

Fujimoto, M., Shimizu, N., Kunii, K., Martyn, J. A., Ueki, K., and Kaneki, M. (2005). A role for iNOS in fasting hyperglycemia and impaired insulin signaling in the liver of obese diabetic mice. Diabetes 54, 1340-1348. doi: 10.2337/diabetes.54. 5.1340

Fulop, T., Jebelovszki, E., Erdei, N., Szerafin, T., Forster, T., Edes, I., et al. (2007). Adaptation of vasomotor function of human coronary arterioles to the simultaneous presence of obesity and hypertension. Arter. Thromb. Vasc. Biol. 27, 2348-2354. doi: 10.1161/ATVBAHA.107.147991

Fulton, D., Gratton, J. P., McCabe, T. J., Fontana, J., Fujio, Y., Walsh, K., et al. (1999). Regulation of endothelium-derived nitric oxide production by the protein kinase Akt. Nature 399, 597-601. doi: 10.1038/21218

Galvez-Prieto, B., Bolbrinker, J., Stucchi, P., de Las Heras, A. I., Merino, B., Arribas, S., et al. (2008). Comparative expression analysis of the renin-angiotensin system components between white and brown perivascular adipose tissue. J. Endocrinol. 197, 55-64. doi: 10.1677/JOE-07-0284

Galvez-Prieto, B., Somoza, B., Gil-Ortega, M., Garcia-Prieto, C. F., de Las Heras, A. I., Gonzalez, M. C., et al. (2012). Anticontractile effect of perivascular adipose tissue and leptin are reduced in hypertension. Front. Pharmacol. 3:103. doi: 10.3389/fphar.2012.00103

Gao, Y. J. (2007). Dual modulation of vascular function by perivascular adipose tissue and its potential correlation with adiposity/lipoatrophy-related vascular dysfunction. Curr. Pharm. Des. 13, 2185-2192. doi: 10.2174/ 138161207781039634

Gao, Y. J., Hirota, S., Zhang, D. W., Janssen, L. J., and Lee, R. M. (2003). Mechanisms of hydrogen-peroxide-induced biphasic response in rat mesenteric artery. Br. J. Pharmacol. 138, 1085-1092. doi: 10.1038/sj.bjp.07 05147

Gao, Y. J., Lu, C., Su, L. Y., Sharma, A. M., and Lee, R. M. K. W. (2007). Modulation of vascular function by perivascular adipose tissue: the role of endothelium and hydrogen peroxide. Br. J. Pharmacol. 151, 323-331. doi: 10.1038/sj.bjp.0707228

Gao, Y. J., Zeng, Z. H., Teoh, K., Sharma, A. M., Abouzahr, L., Cybulsky, I., et al. (2005). Perivascular adipose tissue modulates vascular function in the human internal thoracic artery. J. Thorac. Cardiovasc. Surg. 130, 1130-1136. doi: 10.1016/j.jtcvs.2005.05.028

Garvey, E. P., Oplinger, J. A., Furfine, E. S., Kiff, R. J., Laszlo, F., Whittle, B. J. R., et al. (1997). 1400W is a slow, tight binding, and highly selective inhibitor of inducible nitric-oxide synthase in vitro and in vivo. J. Biol. Chem. 272, 4959-4963. doi: 10.1074/jbc.272.8.4959

Gil-Ortega, M., Condezo-Hoyos, L., Garcia-Prieto, C. F., Arribas, S. M., Gonzalez, M. C., Aranguez, I., et al. (2014). Imbalance between pro and anti-oxidant mechanisms in perivascular adipose tissue aggravates long-term high-fat dietderived endothelial dysfunction. PLoS One 9:e95312. doi: 10.1371/journal.pone. 0095312

Gonzaga, N. A., Awata, W. M. C., do Vale, G. T., Marchi, K. C., Muniz, J. J., Tanus-Santos, J. E., et al. (2018). Perivascular adipose tissue protects against the vascular dysfunction induced by acute ethanol intake: role of hydrogen peroxide. Vascul. Pharmacol. 111, 44-53. doi: 10.1016/j.vph.2018.08.010
Gregersen, S., Samocha-Bonet, D., Heilbronn, L. K., and Campbell, L. V. (2012). Inflammatory and oxidative stress responses to high-carbohydrate and highfat meals in healthy humans. J. Nutr. Metab. 2012:238056. doi: 10.1155/2012/ 238056

$\mathrm{Gu}, \mathrm{P}$., and $\mathrm{Xu}, \mathrm{A}$. (2013). Interplay between adipose tissue and blood vessels in obesity and vascular dysfunction. Rev. Endocr. Metab. Disord. 14, 49-58. doi: 10.1007/s11154-012-9230-8

Jimenez, R., Sanchez, M., Zarzuelo, M. J., Romero, M., Quintela, A. M., LopezSepulveda, R., et al. (2010). Endothelium-dependent vasodilator effects of peroxisome proliferator-activated receptor agonists via the phosphatidylinositol-3 kinase-akt pathway. J. Pharmacol. Exp. Ther. 332, 554-561. doi: 10. 1124/jpet.109.159806

Ketonen, J., Shi, J., Martonen, E., and Mervaala, E. (2010). Periadventitial adipose tissue promotes endothelial dysfunction via oxidative stress in diet-induced obese C57Bl/6 mice. Circ. J. 74, 1479-1487. doi: 10.1253/circj.cj-09-0661

Kikta, D. C., and Fregly, M. J. (1982). Effect of in vitro administration of captopril on vascular reactivity of rat aorta. Hypertension. 4, 118-124. doi: 10.1161/01. HYP.4.1.118

Koliaki, C., Liatis, S., and Kokkinos, A. (2018). Obesity and cardiovascular disease: revisiting an old relationship. Metabolism. 92, 98-107. doi: 10.1016/j.metabol. 2018.10.011

Lee, R. M., Lu, C., Su, L. Y., and Gao, Y. J. (2009). Endothelium-dependent relaxation factor released by perivascular adipose tissue. J. Hypertens. 27, 782-790. doi: 10.1097/HJH.0b013e328324ed86

Lee, S., Evans, M. A., Chu, H. X., Kim, H. A., Widdop, R. E., Drummond, G. R., et al. (2015). Effect of a selective mas receptor agonist in cerebral ischemia in vitro and in vivo. PLoS One 10:e0142087. doi: 10.1371/journal.pone.0142087

Lohn, M., Dubrovska, G., Lauterbach, B., Luft, F. C., Gollasch, M., and Sharma, A. M. (2002). Periadventitial fat releases a vascular relaxing factor. FASEB J. 16, 1057-1063. doi: 10.1096/fj.02-0024com

Ma, L., Ma, S., He, H., Yang, D., Chen, X., Luo, Z., et al. (2010). Perivascular fat-mediated vascular dysfunction and remodeling through the AMPK/mTOR pathway in high-fat diet-induced obese rats. Hypertens. Res. 33, 446-453. doi: 10.1038/hr.2010.11

Majesky, M. W. (2015). Adventitia and perivascular cells. Arter. Thromb. Vasc. Biol. 35, e31-e35. doi: 10.1161/ATVBAHA.115.306088

Malinowski, M., Deja, M. A., Gołba, K. S., Roleder, T., Biernat, J., and Woś, S. (2008). Perivascular tissue of internal thoracic artery releases potent nitric oxide and prostacyclin-independent anticontractile factor. Eur. J. Cardiothoracic Surg. 33, 225-231. doi: 10.1016/j.ejcts.2007.11.007

Mathai, M. L., Chen, N., Cornall, L., and Weisinger, R. S. (2011). The role of angiotensin in obesity and metabolic disease. Endocr. Metab. Immune Disord. Drug. Targets 11, 198-205. doi: 10.2174/187153011796429853

Meddings, J. B., Scott, R. B., and Fick, G. H. (1989). Analysis and comparison of sigmoidal curves: application to dose-response data. Am. J. Physiol. Gastrointest. Liver Physiol. 257(6 Pt 1), G982-G989. doi: 10.1152/ajpgi.1989. 257.6.g982

Navia-Pelaez, J. M., Campos-Mota, G. P., Araujo de Souza, J. C., Aguilar, E. C., Stergiopulos, N., Alvarez-Leite, J. I., et al. (2017). nNOS uncoupling by oxidized LDL: implications in atherosclerosis. Free Radic. Biol. Med. 113, 335-346. doi: 10.1016/j.freeradbiomed.2017.09.018

Nguyen Dinh Cat, A., and Touyz, R. M. (2011). A new look at the renin-angiotensin system-focusing on the vascular system. Peptides 32, 2141-2150. doi: 10.1016/ j.peptides.2011.09.010

Nobrega, N., Araujo, N. F., Reis, D., Facine, L. M., Miranda, C. A. S., Mota, G. C., et al. (2019). Hydrogen peroxide and nitric oxide induce anticontractile effect of perivascular adipose tissue via renin angiotensin system activation. Nitric Oxide 84, 50-59. doi: 10.1016/j.niox.2018.12.011

Oliveira, M. C., Menezes-Garcia, Z., Henriques, M. C., Soriani, F. M., Pinho, V., Faria, A. M., et al. (2013). Acute and sustained inflammation and metabolic dysfunction induced by high refined carbohydrate-containing diet in mice. Obesity 21, E396-E406. doi: 10.1002/oby.20230

Peiró, C., Vallejo, S., Gembardt, F., Palacios, E., Novella, S., Azcutia, V., et al. (2013). Complete blockade of the vasorelaxant effects of angiotensin-(1-7) and bradykinin in murine microvessels by antagonists of the receptor Mas. J. Physiol. 591, 2275-2285. doi: 10.1113/jphysiol.2013.251413

Poirier, P., Giles, T. D., Bray, G. A., Hong, Y., Stern, J. S., Pi-Sunyer, F. X., et al. (2006). Obesity and cardiovascular disease: pathophysiology, evaluation, 
and effect of weight loss: an update of the 1997 American Heart Association Scientific statement on obesity and heart disease from the obesity committee of the council on nutrition physical activity, and metabolism. Circulation 113, 898-918. doi: 10.1161/CIRCULATIONAHA.106.171016

Porto, L. C., Savergnini, S. S., de Castro, C. H., Mario, E. G., Ferreira, A. V., Santos, S. H., et al. (2011). Carbohydrate-enriched diet impairs cardiac performance by decreasing the utilization of fatty acid and glucose. Ther. Adv. Cardiovasc. Dis. 5, 11-22. doi: 10.1177/1753944710386282

Raffai, G., Durand, M. J., and Lombard, J. H. (2011). Acute and chronic angiotensin-(1-7) restores vasodilation and reduces oxidative stress in mesenteric arteries of salt-fed rats. Am. J. Physiol. Hear. Circ. Physiol. 301, H1341-H1352. doi: 10.1152/ajpheart.00202.2011

Rahmouni, K., Correia, M. L., Haynes, W. G., and Mark, A. L. (2005). Obesityassociated hypertension: new insights into mechanisms. Hypertension 45, 9-14. doi: 10.1161/01.HYP.0000151325.83008.b4

Rebolledo, A., Rebolledo, O. R., Marra, C. A., Garcia, M. E., Roldan Palomo, A. R., Rimorini, L., et al. (2010). Early alterations in vascular contractility associated to changes in fatty acid composition and oxidative stress markers in perivascular adipose tissue. Cardiovasc. Diabetol. 9:65. doi: 10.1186/1475-2840-9-65

Ren, Y. L., Garvin, J. L., and Carretero, O. A. (2002). Vasodilator action of angiotensin-(1-7) on isolated rabbit afferent arterioles. Hypertension 39, 799802. doi: 10.1161/hy0302.104673

Rubio-Ruiz, M. E., Del Valle-Mondragon, L., Castrejon-Tellez, V., Carreon-Torres, E., Diaz-Diaz, E., and Guarner-Lans, V. (2014). Angiotensin II and 1-7 during aging in Metabolic Syndrome rats. Expression of AT1, AT2 and Mas receptors in abdominal white adipose tissue. Peptides 57, 101-108. doi: 10.1016/j.peptides. 2014.04.021

Sampaio, W. O., Souza dos Santos, R. A., Faria-Silva, R., da Mata Machado, L. T., Schiffrin, E. L., and Touyz, R. M. (2007). Angiotensin-(1-7) through receptor Mas mediates endothelial nitric oxide synthase activation via Akt-dependent pathways. Hypertension 49, 185-192. doi: 10.1161/01.HYP.0000251865.35 $728.2 \mathrm{f}$

Schling, P., Mallow, H., Trindl, A., and Loffler, G. (1999). Evidence for a local renin angiotensin system in primary cultured human preadipocytes. Int. J. Obes. Relat. Metab. Disord. 23, 336-341. doi: 10.1038/sj.ijo.0800821

Soltis, E. E., and Cassis, L. A. (1991). Influence of perivascular adipose tissue on rat aortic smooth muscle responsiveness. Clin. Exp. Hypertens. 13, 277-296. doi: 10.3109/10641969109042063
Su, J., Palen, D. I., Boulares, H., and Matrougui, K. (2008). Role of ACE/AT2R complex in the control of mesenteric resistance artery contraction induced by ACE/AT1R complex activation in response to Ang I. Mol. Cell. Biochem. 311, 1-7. doi: 10.1007/s11010-007-9686-0

Szasz, T., Bomfim, G. F., and Webb, R. C. (2013). The influence of perivascular adipose tissue on vascular homeostasis. Vasc. Heal. Risk Manag. 9, 105-116. doi: 10.2147/VHRM.S33760

Torrisi, J. S., Hespe, G. E., Cuzzone, D. A., Savetsky, I. L., Nitti, M. D., Gardenier, J. C., et al. (2016). Inhibition of Inflammation and iNOS Improves Lymphatic Function in Obesity. Sci. Rep. 6:19817. doi: 10.1038/srep 19817

Van de Voorde, J., Boydens, C., Pauwels, B., and Decaluwe, K. (2014). Perivascular adipose tissue, inflammation and vascular dysfunction in obesity. Curr. Vasc. Pharmacol. 12, 403-411. doi: 10.2174/15701611126661404232 20628

Wang, G., Li, X., Wang, H., Wang, Y., Zhang, L., Zhang, L., et al. (2015). Later phase cardioprotection of ischemic post-conditioning against ischemia/reperfusion injury depends on iNOS and PI3K-Akt pathway. Am. J. Transl. Res. 7, 26032611.

World Health Organization [WHO] (2016). Obesity and Overweight. Geneva: WHO.

Wu, Z. T., Ren, C. Z., Yang, Y. H., Zhang, R. W., Sun, J. C., Wang, Y. K., et al. (2016). The PI3K signaling-mediated nitric oxide contributes to cardiovascular effects of angiotensin-(1-7) in the nucleus tractus solitarii of rats. Nitric Oxide 52, 56-65. doi: 10.1016/j.niox.2015.12.002

Conflict of Interest: The authors declare that the research was conducted in the absence of any commercial or financial relationships that could be construed as a potential conflict of interest.

Copyright (C) 2021 Reis Costa, Silveira, Campos, Nóbrega, de Araújo, de Figueiredo Borges, dos Santos Aggum Capettini, Ferreira and Bonaventura. This is an openaccess article distributed under the terms of the Creative Commons Attribution License (CC BY). The use, distribution or reproduction in other forums is permitted, provided the original author(s) and the copyright owner(s) are credited and that the original publication in this journal is cited, in accordance with accepted academic practice. No use, distribution or reproduction is permitted which does not comply with these terms. 